\title{
DRUSILASAURA DESEADENSIS GEN. ET SP. NOV., UN NUEVO TITANOSAURIO (DINOSAURIA-SAUROPODA), DE LA FORMACIÓN BAJO BARREAL, CRETÁCICO SUPERIOR DEL NORTE DE SANTA CRUZ, ARGENTINA
}

\author{
CÉSAR NAVARRETE, GABRIEL CASAL \& RUBÉN MARTÍNEZ \\ Laboratorio de Paleovertebrados, Facultad de Ciencias Naturales, Universidad Nacional de la Patagonia \\ San Juan Bosco, km 4, 9009, Comodoro Rivadavia, Chubut, Argentina. \\ cesar21_gn@hotmail.com,paleogac@yahoo.com.br,rdfmartinez@yahoo.com
}

\begin{abstract}
DRUSILASAURA DESEADENSIS GEN. ET SP. NOV., A NEW TITANOSAUR (DINOSAURIASAUROPODA), OF THE BAJO BARREAL FORMATION, UPPER CRETACEOUS OF NORTH OF SANTA CRUZ, ARGENTINA. A new titanosaurid from Patagonia, Argentina, is here described, Drusilasaura deseadensis gen. et sp. nov., the materials include four dorsal vertebrae, one sacral vertebra, six caudal vertebrae, left scapula, dorsal rib fragments, two haemapophyses and indeterminate fragments. The material comes from the Upper Member of the Bajo Barreal Formation (Cenomanian-Turonian), exposed in the María Aike Ranch, Santa Cruz Province, Patagonia, Argentina. The taxon shows the following character association: (i) presence in the anterior dorsal vertebrae, of two robust spinodiapophyseal laminae, one anterior and other posterior, which delimit an elongate and deep supradiapophyseal cavity; (ii) presence in the anterior dorsal vertebra of a small circumneural lamina surrounding the neural canal in posterior view; (iii) the last sacral vertebra with postspinal lamina expanded toward the neural spine apex; (iv) prespinal laminae, at least until $5^{\circ}$ ? caudal vertebra, expanded toward the neural spine apex; (v) existence in the anterior caudal vertebrae of tuberopostzygapophyseal laminae; (vi) presence of ventral foramina, at least until the $4^{\circ}$ ? caudal vertebrae; and (vii) prezygapophyseal tuberosity jointed the prespinal lamina until the $4^{\circ}$ ? caudal vertebrae. The presence of a synapomorfic character of the clade Lognkosauria suggests the probable inclusion of the Drusilasaura deseadensis gen. et sp. nov. within the clade, in tandem with Mendozasaurus neguyelap, Futalognkosaurus dukei and probably Puertasaurus reuili.
\end{abstract}

Key words: Titanosauria, Lognkosauria, Upper Cretaceous, Patagonia Argentina.

RESUMO - Descreve-se aqui um novo titanossauro da Patagônia, Argentina, Drusilasaura deseadensis gen. et sp. nov., a partir de uma série de materiais que incluem quatro vértebras dorsais, uma vértebra sacral, seis vértebras caudais, escápula esquerda, fragmento de costela dorsal, duas hemapófises e fragmentos indeterminados. Este exemplar provém do Membro Superior da Formação Bajo Barreal (Cenomaniano-Turoniano), que aflora na Estância María Aike, Província de Santa Cruz, Patagônia Argentina. O táxon apresenta a seguinte associação de caracteres: (i) presença nas vértebras dorsais anteriores de duas robustas lâminas espino-diapofisais, uma anterior e outra posterior que delimitam uma alongada e profunda cavidade supradiapofisial; (ii) presença de uma pequena lâmina circumneural, que rodeia o canal neural em vista posterior da vértebra dorsal anterior; (iii) última vértebra sacra com lâmina postespinal expandida até o ápice da espinha neural; (iv) vértebras caudais com lâmina pré-espinhais expandidas, até a $5^{\text {a }}$ ? vértebra caudal, em direção ao ápice da espinha neural; (v) existência de lâminas túbero-postzigapofisiais nas vértebras caudais anteriores; (vi) presença de forames ventrais, pelo menos até a $4^{\mathrm{a}}$ ? Caudal; e (vii) tuberosidade prezigapofisial contatando a lâmina pré-espinhal até a $4^{\text {a }}$ ? vértebra caudal. A presença de um carácter sinapomórfico do clado Lognkosauria sugere a provável inclusão de Drusilasaura deseadensis gen. et sp. nov. neste clado, juntamente com Mendozasaurus neguyelap, Futalognkosaurus dukei e, provavelmente, Puertasaurus reuili.

Palavras-chave: Titanosauria, Lognkosauria, Cretáceo Superior, Patagônia Argentina.

\section{INTRODUCCIÓN}

Los titanosaurios son los saurópodos dominantes en el Cretácico Superior de Sudamérica (Bonaparte, 1986; Salgado \& Coria, 1996; Powell, 2003) con un registro especialmente rico en la región patagónica (Bonaparte, 1986; Powell, 1987; Calvo \& Bonaparte, 1991; Salgado \& Coria, 1993; Martínez, 1998; Salgado \& Azpilicueta, 2000; González Riga, 2003; Calvo \& González Riga, 2003; Apesteguía, 2004; Martínez et al.,
2004; Calvo et al., 2007a; Filippi \& Garrido, 2008, entre otros). La Formación Bajo Barreal ha permitido documentar la existencia de titanosaurios especialmente importantes para el conocimiento del clado, como Epachthosaurus sciuttoi Powell, 1990, Argyrosaurus superbus Lydekker, 1893 y Aeolosaurus colhuehuapensis Casal et al., 2007 (in Martínez et al., 2004; Lydekker, 1893; Casal et al., 2007, respectivamente) además de otros materiales fragmentarios o en estudio como un cráneo de Titanosauriformes (Martínez, 1998; 
Martínez et al., 2006; Martínez et al., 2009), nuevos materiales de Epachthosaurus (Casal \& Ibiricu, 2010) y vértebras caudales comparables con Andesaurus (Calvo \& Bonaparte, 1991).

El presente trabajo tiene como objetivo presentar y describir un nuevo titanosaurio proveniente de la Formación Bajo Barreal, del Cretácico Superior en la provincia de Santa Cruz, Argentina. Así como también compararlo con otras especies de titanosaurios y establecer relaciones de parentesco.

\section{GEOLOGÍA Y TAFONOMÍA}

Los materiales MPM-PV 2097, ya mencionados por Navarrete et al. (2008), fueron extraídos en el sector norte de la provincia de Santa Cruz, en afloramientos cretácicos del borde sur de la Cuenca del Golfo San Jorge, aledaños a la región del Macizo del Deseado (Leanza, 1958) (Figura 1).

A fines del Jurásico y durante el Cretácico la Cuenca del Golfo San Jorge fue colmatada por un conjunto de sedimentos piroclásticos y epiclásticos que, continuados hasta el Mioceno (Umazano et al., 2007), alcanzan un espesor superior a los 5000 m (Uliana \& Legarreta, 1999). El Macizo del Deseado constituía entonces el relieve positivo que controlaba la cuenca por el sur y actuaba como barrera geomorfológica. Por ello los fósiles, como los descriptos en este trabajo, sólo se encuentran en las secuencias tardías del Cretácico Superior de la Formación Bajo Barreal y de la Formación Laguna Palacios (Lesta \& Ferello, 1972), integrantes del Grupo Chubut (Lesta \& Ferello, 1972); mientras que las unidades jurásico-cretácicas que las infrayacen se restringen a los sectores centrales de la cuenca.

La Formación Bajo Barreal (Figura 1), de donde provienen los materiales estudiados, tiene importancia paleontológica debido a su abundante contenido de restos de tetrápodos fósiles. La misma es subdividida informalmente en dos miembros, Inferior y Superior (Sciutto, 1981). Puntualmente, en la zona de trabajo, la Formación Bajo Barreal es representada por la sección superior del Miembro Inferior y la totalidad del Miembro Superior con un espesor conjunto aproximado de $150 \mathrm{~m}$. El Miembro Inferior está constituido por areniscas verde-grisáceas bien consolidadas expuestas como reducidas cornisas resistentes a la erosión e intercaladas con bancos pelíticos blanquecinos. Las areniscas presentan estructuras entrecruzadas difusas, que se interpretan como generadas por la migración de formas de lecho arenosas en sistemas fluviales de alta sinuosidad. En el Miembro Superior dominan las pelitas y fangolitas grises a castañas, con moderada a baja consolidación, que constituyen lomadas de tipo bad lands. Las fangolitas son macizas o con laminación paralela difusa y se interpretan como correspondientes a depósitos de planicies de inundación con una fuerte participación piroclástica. Se intercalan bancos lenticulares de areniscas fluviales finas a medianas de escasa potencia, que en algunos casos corresponden a rellenos de canal y en otros a lóbulos de desbordamiento.

La investigación demuestra que para la Formación Bajo Barreal existe una marcada supremacía de restos fósiles de saurópodos y terópodos, representados por huesos y dientes provenientes de los niveles superiores del Miembro Inferior, sugiriendo un mayor potencial de preservación. Por el contrario, en la mitad superior del Miembro Superior (Figura 1), con abundancia de fangolitas y escasos restos óseos que sugieren condiciones desfavorables se realizó el hallazgo que se comunica.

Las observaciones tafonómicas preliminares realizadas durante la extracción del material, permiten diferenciar una

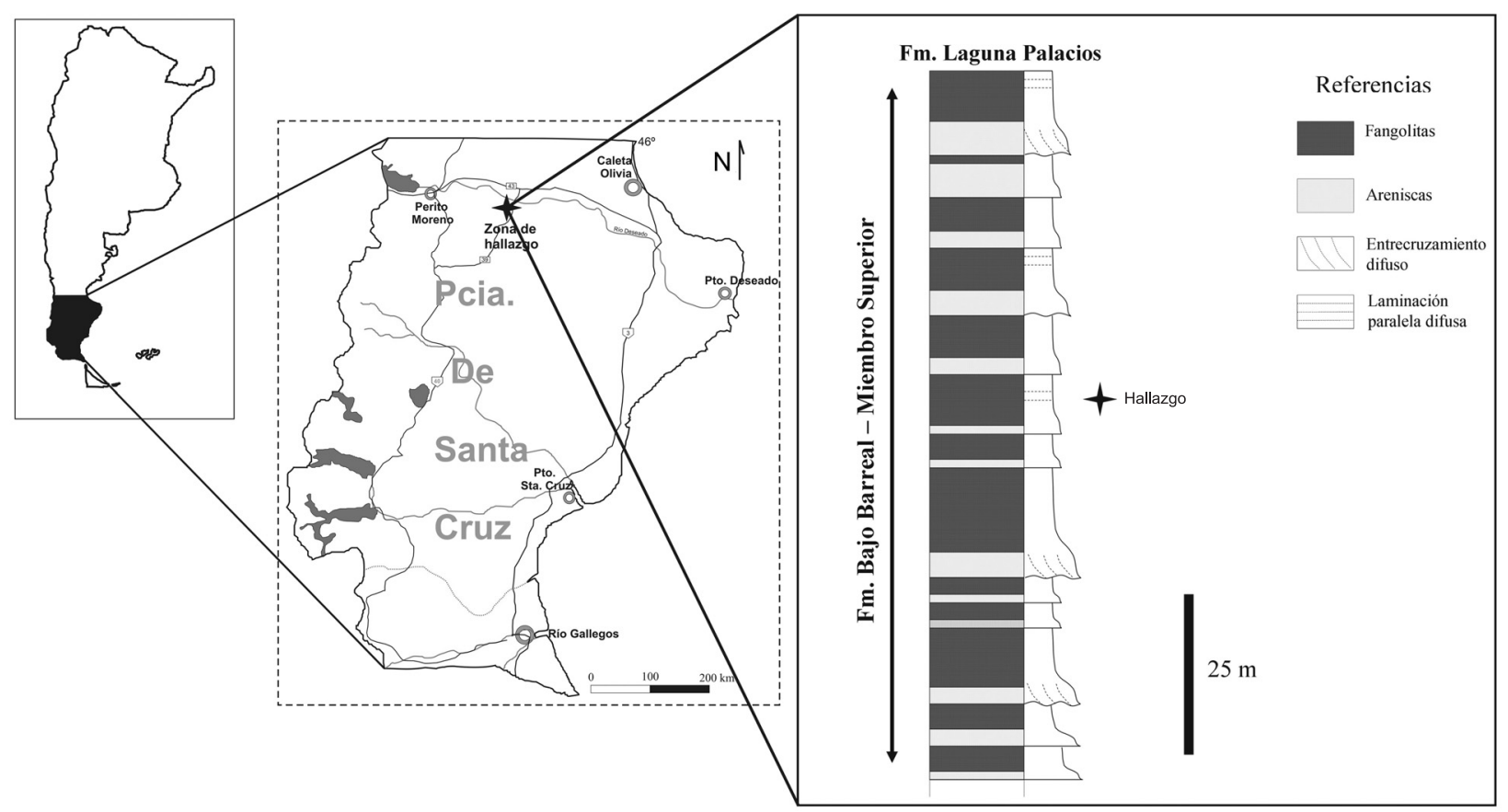

Figura 1. Mapa de ubicación geográfica y columna estratigráfica del área de estudio.

Figure 1. Geographic location map and stratigraphic column of the study area. 
etapa bioestratinómica y otra fósil-diagenética (sensu González Riga \& Astini, 2007). La primera surge de evidencias de exposición subaérea previa al sepultamiento, con efectos erosivos y meteóricos sobre los huesos; una parcial desarticulación y reorientación de los restos óseos con una dirección dominante NW-SE. La segunda etapa se manifiesta a partir de una importante deformación de origen litostático sobre las vértebras dorsales fundamentalmente y un intenso fracturamiento en la escápula izquierda. Litológicamente el banco de areniscas que incluía a los materiales presenta una elevada participación de arcillas y material piroclástico de caída, así como una ausencia de estructuras tractivas. Estas características permiten interpretarlo preliminarmente como producto de un depósito de desbordamiento proximal que no permitió la selección del sedimento. La alta densidad del medio, dada por la carga sedimentaria pelítica, proveyó la suficiente energía como para desarticular parcialmente el esqueleto y orientarlo con un escaso transporte. Esta última interpretación se basa en que, en depósitos fósiles, la diferencia de tamaño de grano entre los sedimentos portadores y los restos óseos permite evaluar la historia de transporte (Behrensmeyer, 1990). La presencia de cuarzo equivalente con tamaños relativos similares, se interpreta como indicativo de que fueron transportados e hidráulicamente ordenados. En cambio, si hubieran estado asociados a sedimentos con cuarzo equivalente mucho más fino, se deduciría un transporte mínimo. Debe considerarse sin embargo que la relación de transporte y cuarzo equivalentes puede estar influenciada por la morfología de los restos fósiles (Behrensmeyer, 1990).

\section{MATERIAL Y MÉTODOS}

El conjunto de materiales objeto de este estudio, proviene de afloramientos de la Formación Bajo Barreal situados en el norte de la provincia de Santa Cruz, Argentina. Específicamente en el departamento Lago Buenos Aires a aproximadamente $70 \mathrm{~km}$ al sur oeste de la localidad de Las Heras y a unos $120 \mathrm{~km}$ al sur este de Perito Moreno. Los restos fueron avistados por el paleontólogo Marcelo Tejedor, mientras recorría la zona en busca de mamíferos mesozoicos, quien personalmente informó de esto al personal del Laboratorio de Paleontología de Vertebrados de la UNPSJB en Comodoro Rivadavia, que decidió su extracción y estudio.

Los materiales rescatados se componen de 4 vértebras dorsales, 1 vértebra sacra, 6 vértebras caudales, 1 escápula izquierda, fragmentos de costillas, 2 hemapófisis y fragmentos indeterminados. De estos, 3 vértebras dorsales se encontraron con un estado de preservación malo por lo que su estudio no fue posible y sólo pudo utilizarse una de ellas, mientras que el resto del material fue utilizado para el estudio.

Para la preparación y estudio de los materiales se utilizaron las instalaciones e instrumental del Laboratorio de Paleontología de Vertebrados de la UNPSJB en Comodoro Rivadavia. Luego fueron depositados en el Museo Padre Molina de la ciudad de Río Gallegos, Santa Cruz, Argentina.
Abreviaturas institucionales. IANIGLA-PV, Instituto Argentino de Nivología, Glaciología y Ciencias Ambientales, Mendoza, Argentina; MCT, Museu de Ciências da Terra, Rio de Janeiro, Brasil; MPM-PV, Museo Padre Molina, Paleontología de Vertebrados, Río Gallegos, Santa Cruz, Argentina; MUCPv, Museo Universidad del Comahue, Neuquén, Argentina; UNPSJB, Universidad Nacional de la Patagonia San Juan Bosco, Comodoro Rivadavia, Chubut, Argentina.

\section{PALEONTOLOGÍA SISTEMÁTICA}

\author{
DINOSAURIA Owen, 1842 \\ SAURISCHIA Seeley, 1888 \\ SAUROPODA Marsh, 1878 \\ TITANOSAURIA, Bonaparte \& Coria, 1993 \\ TITANOSAURIDAE Lydekker, 1893 \\ LOGNKOSAURIA?Calvo, Porfiri, González Riga \& Kellner, 2007 \\ Drusilasaura gen. nov.
}

Etimología. Drusilasaura, "Drusila” en homenaje a Drusila Ortiz de Zárate, joven voluntaria en la excavación del saurópodo e integrante de la familia propietaria de la estancia "María Aike"; "saura", griego, femenino de lagarto.

Especie tipo. Drusilasaura deseadensis sp. nov.

Diagnosis. Titanosaurio de gran tamaño caracterizado por la siguiente asociación de caracteres: (i) presencia en las vértebras dorsales anteriores, de dos robustas láminas espinodiapofisiales, una anterior y otra posterior que delimitan una elongada y profunda cavidad supradiapofisial; (ii) presencia de una pequeña lámina circumneural, que rodea el canal neural en vista posterior de la vértebra dorsal anterior; (iiii) última vértebra sacra con la lámina postespinal expandidas hacia el ápice de la espina neural; (iv) lámina prespinal expandidas hacia el ápice de la espina neural en al menos hasta la $5^{\circ}$ ? vértebra caudal; (v) existencia de láminas tuberopostzigapofisiales en las vértebras caudales anteriores; (vi) presencia de forámenes ventrales en al menos la $4^{\circ}$ ? vértebra caudal; (vii) tuberosidad prezigapofisial contactando la lámina prespinal hasta la $4^{\circ}$ ? vértebra caudal.

English diagnosis. Large sized titanosaurid characterized for the following associated characters: (i) occurrence in the anterior dorsal vertebrae, of two robust spinodiapophyseal laminae, one anterior and other posterior, which delimit an elongate and deep supradiapophyseal cavity; (ii) presence in the anterior dorsal vertebra of a small circumneural lamina surrounding the neural canal in posterior view; (iii) the last sacral vertebra with postspinal lamina expanded toward the neural spine apex; (iv) prespinal laminae, at least until $5^{\circ}$ ? caudal vertebra, expanded toward the neural spine apex; (v) existence in the anterior caudal vertebrae of tuberopostzygapophyseal laminae; (vi) presence of ventral foramina, at least until the $4^{\circ}$ ? caudal vertebrae; and (vii) prezygapophyseal tuberosity jointed the prespinal lamina until the $4^{\circ}$ ? caudal vertebrae. 


\section{Drusilasaura deseadensis sp.nov.}

(Figuras 2-9)

Etimología. "Deseadensis" en relación al valle del río Deseado donde fue hallado el saurópodo.

Diagnosis. La misma que para el género.

English diagnosis. The same for the genus.

Holotipo. MPM-PV 2097/1 al 2097/19. Cuatro vértebras dorsales, una vértebra sacra, seis vértebras caudales, escápula izquierda, segmento de costilla dorsal y fragmentos indeterminados.

Ubicación geográfica. El sitio del hallazgo se ubica en la margen sur del río Deseado, en la estancia María Aike, Departamento Lago Buenos Aires, provincia de Santa Cruz, Argentina (Figura 1). Coordenadas geográficas 46 43'05" $\mathrm{S}$ y 69³9'55'O.

Ubicación estratigráfica. Banco de areniscas gruesas a medianas y con alta participación de pelitas, intercalado entre fangolitas de la mitad superior del Miembro Superior de la Formación Bajo Barreal (Figura 1).

Edad. La edad asignada a esta unidad litoestratigráfica ha variado según diversos autores: Senoniano (Bonaparte \& Gasparini, 1979), Albiano-Cenomaniano (Archangelsky et al., 1994), Cenomaniano medio-Turoniano tardío (Gradstein et al., 1995, 1997; Bridge et al., 2000) y Cenomaniano tardíoTuroniano temprano (Lamanna et al., 2002). Los estudios de la fauna dinosauriana y sus correlaciones con unidades equivalentes de la cuenca neuquina, sugieren que la edad de la Formación Bajo Barreal asignada por Gradstein et al. (1995, 1997), Bridge et al. (2000) y Lamanna et al. (2002) sería la que más se ajusta a estos vínculos faunísticos.

Descripción. Vértebras dorsales. La vértebra dorsal MPMPV 2097/1, es la más anterior preservada. Presenta un centro vertebral relativamente corto y deprimido dorsoventralmente mientras que las caras lateral y ventral son cóncavas ánteroposteriormente. El pleurocelo tiene forma de ojo acuminado posteriormente, sinapomorfía esta de Titanosauria (Bonaparte \& Coria, 1993; Salgado et al., 1997). Las diapófisis se proyectan lateralmente de manera horizontal y están reforzadas por una lámina paradiapofisial, una lámina centrodiapofisial posterior, una filosa lámina prezigadiapofisial y robustas láminas espinodiapofisiales anterior y posterior. Estas últimas surgen de una única lámina que recorre la espina neural y que en su camino hacia la diapófisis sufre una bifurcación justo antes de dejar la espina y comenzar a horizontalizarse. Internamente estas láminas delimitan una profunda cavidad de contorno oval, elongada lateralmente (Figura 2A). La morfología de estas láminas espinodiapofisiales anterior y posterior, y la profunda cavidad que se genera entre estas, llamada aquí cavidad supradiapofisial, se considera un carácter autapomórfíco de Drusilasaura deseadensis gen. et sp. nov. La lámina postzigodiapofisial se halla muy reducida. Entre las láminas paradiapofisial y centrodiapofisial posterior se observa una cavidad infradiapofisial de contorno subtriangular la cual, si bien es clara, está dañada.

Las parapófisis se encuentran en la base del arco neural, inmediatamente por encima del pleurocelo, existiendo una pequeña lámina centroparapofisial. La articulación hipósfenohipantro está ausente.

Las prezigapófisis se encuentran relativamente altas sobre el centro vertebral, son robustas, inclinadas medialmente y conectadas entre sí por una filosa lámina intraprezigapofisial. A su vez esta última se halla soportada por dos delgadas láminas centroprezigapofisial que rodean al canal neural y que recorren desde el centro vertebral hasta la lámina intraprezigapofisial (Figura 2B). Se observa una importante lámina prezigoparapofisial, la cual en su porción más baja parece tener una leve bifurcación; también, como se mencionó anteriormente, existe una filosa lámina prezigodiapofisial. Las láminas prezigodiapofisial, paradiapofisial y prezigoparapofisial delimitan una amplia cavidad de contorno triangular que está elongada dorsoventralmente. No hay evidencia de láminas espinoprezigapofisiales.

Las postzigapófisis son muy robustas y muestran superficies articulares ovales medialmente inclinadas. Están reforzadas por una gruesa lámina espinopostzigapofisial y por una importante lámina centropostzigapofisial casi vertical, solo levemente abierta cerca del centro vertebral (Figura 2C).

Como es propio de titanosaurios derivados, la lámina espinopostzigapofisial no se halla dividida longitudinalmente en dos ramas (Salgado et al., 2006). Esta lámina contacta distalmente con la lámina espinodiapofisial posterior, lo que genera una profunda cavidad supradiapofisial de geometría elipsoidal y elongada dorsoventralmente. Esta cavidad está limitada en su porción inferior por la pequeña lámina postzigadiapofisial que contacta a la lámina espinodiapofisial posterior a la altura en la que ésta comienza a horizontalizarse. Existe una lámina intrapostzigapofisial de recorrido oblicuo a las facetas articulares de las postzigapófisis y que conecta la superficie de éstas con la base de la lámina postespinal. Justo por debajo de ella se halla el canal neural rodeado por una estructura laminar que sobresale de la superficie posterior de la vértebra. Esta conspicua estructura, llamada aquí lámina circumneural (Figura 2C), tiene como base la cara dorsal de la faceta articular posterior del centro vertebral y rodea por completo al canal neural, carácter considerado como autapomorfía de Drusilasaura deseadensis gen. et sp. nov.

La espina neural, conservada hasta su porción media, es baja, simple y proyectada verticalmente. Las láminas pre y postespinal se desarrollan hasta la base de la espina neural. La lámina prespinal no se halla bifurcada en su base, donde toma contacto con la lámina intraprezigapofisial. No se observan láminas espinoprezigapofisiales ni tampoco espinodiapofisiales accesorias.

Las otras tres vértebras dorsales recuperadas (MPM-PV 2097/2, 2079/3 y 2079/4), más posteriores, se encuentran severamente dañadas y no permiten una descripción adecuada.

Vértebra sacra. Se ha rescatado la última vértebra sacra, MPM-PV 2097/5, la cual se presenta notablemente comprimida antero-posteriormente mostrando un centro vertebral procélico muy corto, con una relación largo/alto de aproximadamente 0.7 , y con caras lateral y ventral cóncavas 
ánteroposteriormente. En ésta el arco neural es alto, se proyecta verticalmente y ocupa un poco más de la mitad del alto total de la vértebra. La espina neural si bien es prácticamente vertical, posee una proyección posterior en su porción media proximal para luego verticalizarse distalmente. Esta modificación en su recorrido provoca que en vista lateral (Figura 3A) se describa una curvatura sigmoidal en la estructura, siendo además transversalmente elongada siendo más ancha que larga y se encuentra reforzada por robustas láminas pre y postespinales. Éstas últimas se expanden notoriamente y de manera continua en su recorrido hacia el ápice de la espina neural (Figura 3B). Las prezigapófisis se hallan aproximadamente a media altura de la vértebra, están orientadas medialmente y presentan una faceta articular pequeña no claramente visible por problemas de conservación (Figura 3C). Son soportadas por láminas centroprezigodiapofisiales y espinoprezigapofisiales. Las láminas espinopostzigapofisial y la espinoprezigapofisial no llegan a contactarse pero igualmente delimitan internamente una cavidad interzigapofisial, de contorno oval y elongada dorsalmente. Inmediatamente por debajo de esta cavidad se observa una segunda cavidad menor de contorno subcircular que estaría ubicada contigua a las postzigapófisis (mal conservadas), en la base de la espina neural.

Las postzigapófisis se hallan muy mal preservadas y en apariencia se hallarían medialmente orientadas. Están reforzadas por las láminas centropostzigapofisiales y las espinopostzigapofisiales. Estas últimas muestran una sensible divergencia desde las postzigapófisis hacia el ápice de la espina neural lo que confiere a ésta una expansión dorsal. En apariencia no existirían láminas espinoprezigapofisiales como tampoco bifurcaciones de la lámina prespinal que contacten con la prezigapófisis, aunque esto puede estar modificado por mala preservación del material en esa zona.
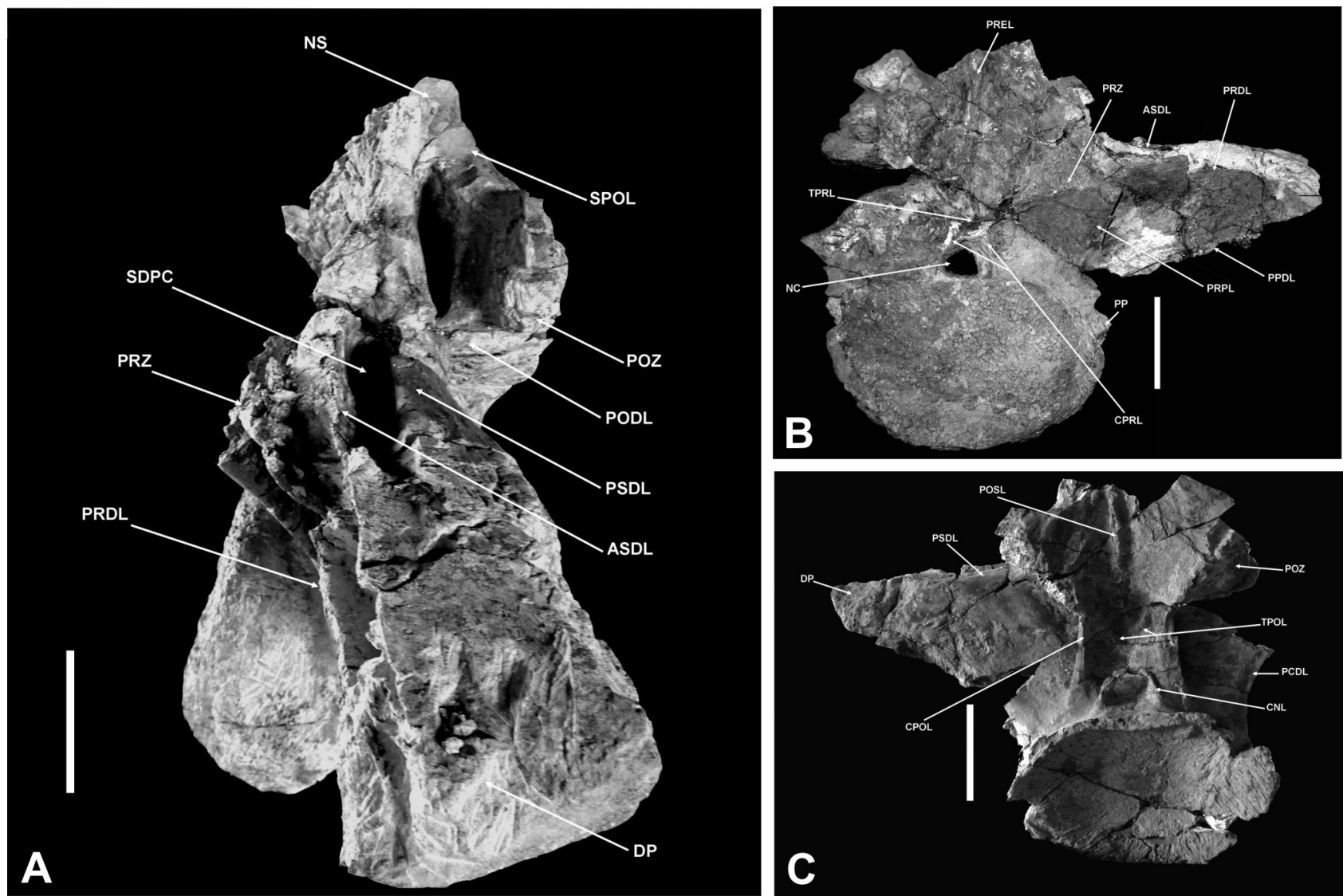

Figura 2. Drusilasaura deseadensis gen. et sp. nov., MPM-PV 2097/1. A, primera vértebra dorsal en vista laterodorsal; B, primera vértebra dorsal en vista anterior; C, primera vértebra dorsal en vista posterior. Abreviaturas: ASDL, lámina espinodiapofisial anterior; CNL, lámina circumneural; CPOL, lámina centropostzigapofisial; CPRL, lámina centroprezigapofisial; DP, diapófisis; NC, canal neural; NS espina neural; PCDL; lámina centrodiapofisial posterior; PODL, lámina postzigadiapofisial; POSL, lámina postespinal; POZ, postzigapófisis; PP, parapófisis; PPDL, lámina paradiapofisial; PRDL, lámina prezigodiapofisial; PREL, lámina prespinal; PRPL, lámina prezigaparapofisial; PRZ, prezigapófisis; PSDL, lámina espinodiapofisial posterior; SDPC, cavidad supradiapofisial; SPOL, lámina espinopostzigapofisial; TPOL, lámina intrapostzigapofisial; TPRL: lámina intraprezigapofisial. Escalas $=10 \mathrm{~cm}$.

Figure 2. Drusilasaura deseadensis gen. et sp. nov., MPM-PV 2097/1. A, first dorsal vertebra in laterodorsal view; B, first dorsal vertebra in anterior view; C, first dorsal vertebra in posterior view. Abbreviations: ASDL, anterior spinodiapophyseal lamina; CNL, circumneural lamina; CPOL, centropostzygapophyseal lamina; CTPRL, centroprezygapophyseal lamina; DP, diapophysis; NC, neural canal; NS, neural spine; PCDL, posterior centrodiapophyseal lamina; PODL, postzygadiapophyseal lamina; POSL, postspinal lamina; POZ, postzygapophysis PP, parapophysis; PPDL, paradiapophyseal lamina; PRDL, prezygodiapophyseal lamina; PREL, prespinal lamina; PRPL, lámina prezigaparapofisial; PRZ, prezygapophysis; PSDL, posterior spinodiapophyseal lamina; SDPC, cavidad supradiapophyseal cavity; SPOL, spinopostzygapophyseal lamina; TPOL, intrapostzygapophyseal lamina; TPRL, intraprezygapophyseal lamina. Scale bars = $10 \mathrm{~cm}$. 
Vértebras caudales. Las vértebras caudales rescatadas presentan centros vertebrales fuertemente procélicos, ausencia de pleurocelos, procesos transversos robustos, relativamente cortos y proyectados posteriormente. La secuencia caudal recuperada comienza con material fragmentario de dos vértebras caudales anteriores articuladas. Se ha preservado sólo parte del arco neural de la más anterior de estas (MPM-PV 2097/6), mientras que en la siguiente, (MPM-PV 2097/7), se conserva el centro vertebral y sólo una pequeña porción del arco neural. Como estas dos vértebras se hallan a su vez soldadas a otras dos vértebras caudales más posteriores, se dificulta su observación, siendo sólo posible una vista lateral (Figura 4). Refiriéndonos a la más anterior de estas (MPM-PV 2097/ 6), ya que es la que permite una mejor descripción gracias a su estado de conservación del arco neural, muestra una espina neural transversalmente expandida, siendo más ancha que larga, orientada posteriormente. Robustas láminas espinoposgtzigapofisiales y espinoprezigapofisiales. Esta última es interceptada antes de contactar la prezigapófisis por una estructura denominada tuberosidad prezigapofisial (Kellner et al., 2005), la cual constituye un punto elevado detrás de cada prezigapófisis y corresponde al borde dorsal del proceso transverso (Figura 4). El proceso transverso conservado es soportado ventralmente por las láminas centrodiapofisiales anterior y posterior. Por problemas de conservación no es posible observar si las láminas pre y postespinales se expanden o no distalmente como ya se observó en la última vértebra sacra y es muy evidente en las vértebras que continúan en la secuencia caudal.
Se interpreta que estas son los elementos caudales más anteriores rescatados, probablemente $1^{\circ}$ ? (MPM-PV 2097/6) y $2^{\circ}$ ? (MPM-PV 2097/7), teniendo en cuenta la altura relativamente superior de la espina neural en relación a las caudales más posteriores, la robustez de la tuberosidad prezigapofisial y que ésta interrumpe a la lámina espinoprezigapofisial de manera notoria antes de que tome contacto con la prezigapófisis (Figura 4). Como se verá más adelante la interrupción de la lámina espinoprezigapofisial provocada por la tuberosidad prezigapofisial se produce hasta cierto punto de la secuencia caudal.

Continúan posteriormente dos vértebras caudales anteriores articuladas (MPM-PV 2097/8 y MPM-PV 2097/9), 3? y $4^{\circ}$ ?, mejor preservadas (Figura 5A), en donde la cara ventral del centro vertebral de la $4^{\circ}$ ? vértebra caudal posee dos prominentes bordes longitudinales que limitan la cara y definen una depresión ventral longitudinal. Esta depresión internamente posee dos pequeñas y profundas oquedades de forma oval, cuyo eje mayor tiene aproximadamente $2 \mathrm{~cm}$ y a las cuales llamaremos aquí forámenes ventrales (Figura 5B). Este carácter es considerado como un rasgo autapomórfico de Drusilasaura deseadensis gen. et sp. nov. Los procesos transversos son soportados por las robustas láminas centrodiapofisial posterior y anterior. Dorsalmente los procesos transversos se continúan con la tuberosidad prezigapofisial, la cual constituye un punto elevado detrás de las prezigapófisis otorgándoles un aspecto aliforme en vista anterior a las vértebras. Esta tuberosidad es reforzada posteriormente por una lámina novedosa que denominamos lámina tuberopostzigapofisial que comunica la tuberosidad
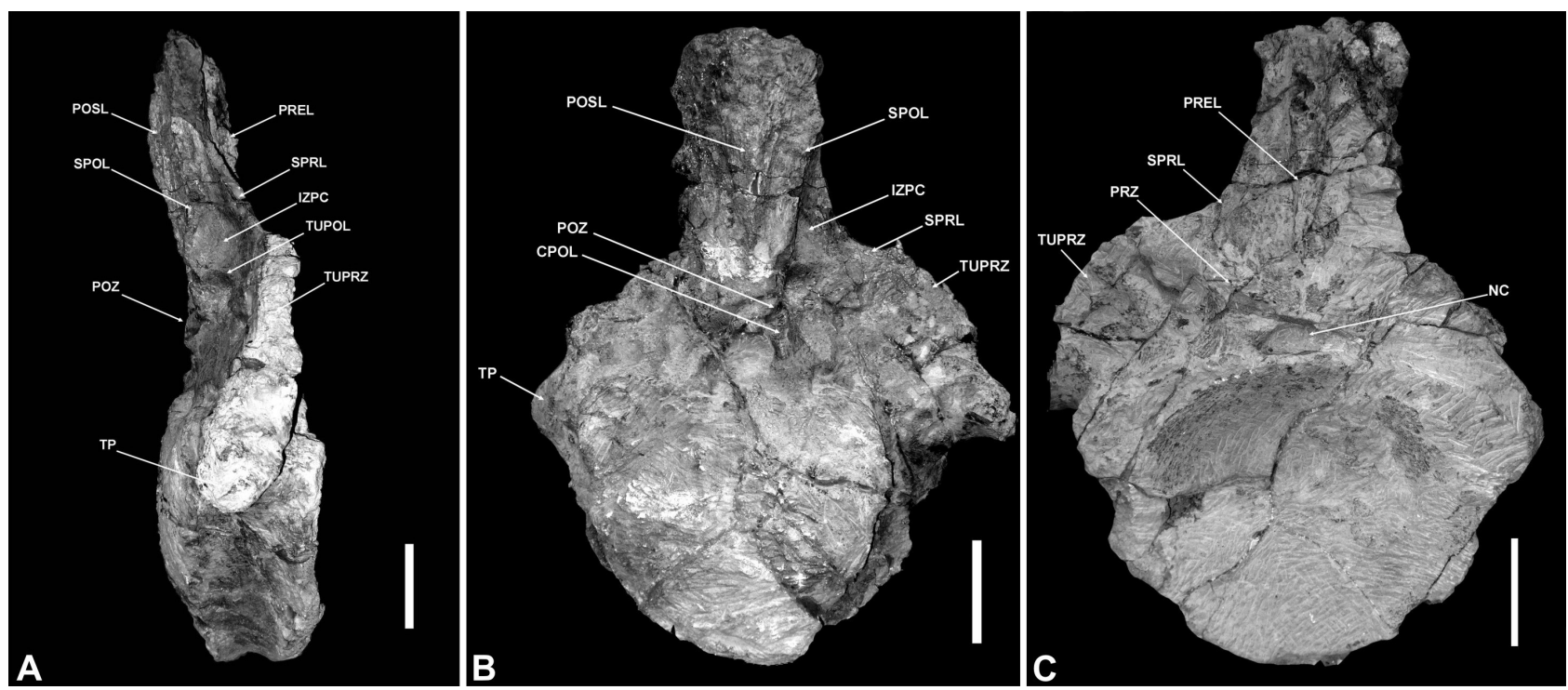

Figura 3. Drusilasaura deseadensis gen. et sp. nov., MPM-PV 2097/5. A, última vértebra sacra en vista lateral; B, última vértebra sacra en vista posterior; C, última vértebra sacra en vista anterior. Abreviaturas: CPOL, lámina centropostzigapofisial; IZPC, cavidad interzigapofisial; NC, canal neural; POSL, lámina postespinal; PREL, lámina prespinal; POZ, postzigapófisis; PRZ, prezigapófisis; SPOL, lámina espinopostzigapofisial; SPRL, lámina espinoprezigapofisial; TP, proceso transverso; TUPOL, lámina tuberopostzigapofisial; TUPRZ, tuberosidad prezigapofisial. Escalas $=10 \mathrm{~cm}$.

Figure 3. Drusilasaura deseadensis gen. et sp. nov., MPM-PV 2097/5. A, last sacral vertebra in lateral view; B, last sacral vertebra in posterior view; C, last sacral vertebra in anterior view. Abbreviations: NC, neural canal; CPOL, centropostzygapophyseal lamina; IZPC interzygapophyseal cavity; POSL, postspinal lamina; POZ, postzygapophysis; PREL, prespinal lamina; PRZ, prezygapophysis; SPOL, spinopostzygapophyseal lamina; SPRL, spinoprezygapophyseal lamina; TP, transverse process; TUPOL, tuberopostzygapophyseal lamina; TUPRZ, prezygapophyseal tuberosity. Scale bars $=10 \mathrm{~cm}$. 
prezigapofisial con la postzigapófisis y, que se considera como un rasgo autapomórfico de Drusilasaura deseadensis gen. et sp. nov. (Figura 5A). Observando la secuencia caudal es importante hacer notar que esta tuberosidad prezigapofisial interrumpe la lámina espinoprezigapofisial hasta la que se interpreta como la $4^{\circ}$ ? vértebra caudal (Figura 6). Teniendo en cuenta que el único antecedente para esta estructura se describe en Baurutitan britoi Kellner, Campos \& Trotta, 2005, y en éste la interrupción sólo se da hasta la $2^{\circ}$ vértebra caudal, la interrupción aquí observada hasta la $4^{\circ}$ ? caudal, se considera como un carácter derivado de Drusilasaura deseadensis gen. et $\mathrm{sp}$. nov. En la $5^{\circ}$ vértebra caudal, descrita luego (MPM-PV 2097/10) esta estructura no alcanza a contactar dicha lámina haciéndose cada vez de menor importancia. El arco neural es de mayor altura que el centro vertebral, es amplio ánteroposteriormente y ocupa la mayor parte del centro ubicándose en su borde anterior. Las prezigapófisis tienen sus extremos distales dañados pero parecerían no ser muy extendidas; están fuertemente soportadas por láminas espinoprezigapofisiales llamativamente robustas. Las postzigapófisis son de contorno oval con su eje mayor orientado dorsoventralmente y están ubicadas inmediatamente por encima del centro vertebral. La lámina espinopostzigapofisial esta bien desarrollada y no se conecta con la espinoprezigapofisial. En vista anterior y posterior se observa que las láminas prespinal y postespinal son muy robustas, prominentes y se expanden distalmente de manera muy marcada, como ya se observó en la vértebra sacra. En vista dorsal la espina neural esta notablemente expandida lateralmente, siendo más ancha que larga, como en los elementos caudales anteriores y la última vértebra sacra (Figura 5C).

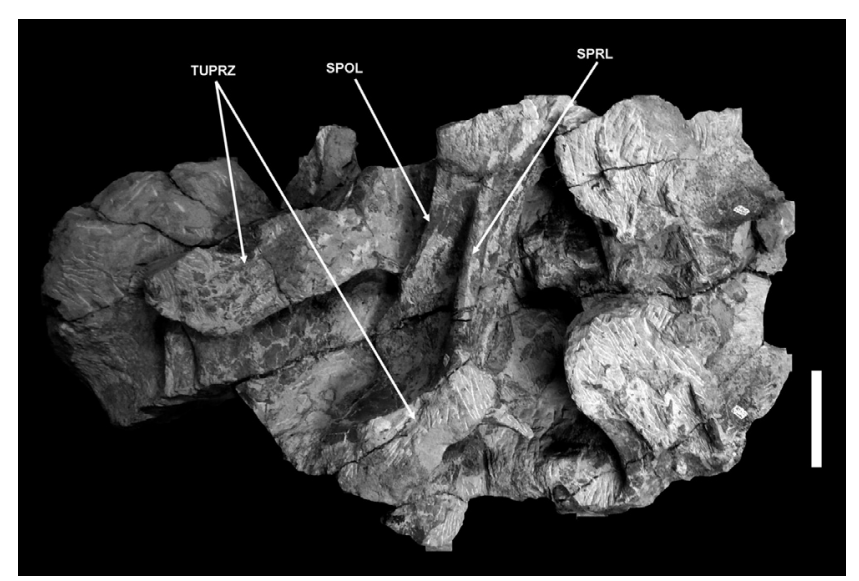

Figura 4. Drusilasaura deseadensis gen. et sp. nov., MPM-PV $2097 / 6$ y $/ 7,1^{\circ}$ ? y $2^{\circ}$ ? vértebra caudal, soldadas con la $3^{\circ}$ ? y $4^{\circ}$ ? vértebras caudales MPM-PV 2097/8 y /9. Abreviaturas: SPOL, lámina espinopostzigapofisial; SPRL, lámina espinoprezigapofisial; TUPRZ, tuberosidad prezigapofisial. Escala $=10 \mathrm{~cm}$.

Figure 4. Drusilasaura deseadensis gen. et sp. nov., MPM-PV $2097 / 6$ and $/ 7,1^{\circ}$ and $2^{\circ}$ caudal vertebrae, fused with $3^{\circ}$ ? and $4^{\circ}$ ? caudal vertebrae MPM-PV 2097/8 y /9. Abbreviations: SPOL, spinopostzygapophyseal lamina; SPRL, spinoprezygapophyseal lamina; TUPRZ, prezygapophyseal tuberosity. Scale bar $=10 \mathrm{~cm}$.
Luego en la secuencia caudal rescatada de este nuevo titanosaurio existe otra vértebra caudal, $5^{\circ}$ ?, bien conservada (MPM-PV 2097/10) y con signos de deformación por aplastamiento. Esto causa que la espina neural se halle fracturada y desplazada pósteroventralmente. Muestra una espina neural transversalmente expandida como en los elementos caudales anteriores, por lo que este carácter se mantiene aún hasta la $5^{\circ}$ ? vértebra caudal. La tuberosidad prezigapofisial se ve reducida en relación a vértebras más anteriores (Figura 6). La lámina prespinal continua siendo de notable robustez y mostrando, como en los elementos caudales anteriores, una marcada expansión hacia el ápice de la espina neural. Por lo que esta expansión de la lámina prespinal en, al menos hasta la $5^{\circ}$ ? vértebra caudal se considera como un rasgo autapomórfico de Drusilasaura deseadensis gen. et sp. nov. Esta vértebra muestra en la cara ventral del centro vertebral un arco hemal soldado y medianamente bien conservado.

Finalizando la secuencia caudal recuperada existe una vértebra caudal anterior de moderado grado de conservación (MPM-PV 2097/11) (Figura 6). Sólo es posible apreciar de ésta una pequeña porción del arco neural que muestra una espinal neural ya expandida longitudinalmente y un centro vertebral fuertemente procélico afectado por una fuerte deformación que lo comprimió lateralmente.

Escápula. Se ha recuperado una escápula izquierda (MPMPV 2097/14) (Figura 7) de $143 \mathrm{~cm}$ de longitud cuyo estado de preservación no es bueno, presentándose muy fracturada como consecuencia de la presión litostática actuante. La hoja escapular posee un borde anterior cóncavo en todo su recorrido, lo que genera una depresión elongada próximodistalmente. En vista lateral es marcadamente convexa. La fosa supracoracoidea esta suavemente delineada. El borde dorsal es levemente cóncavo y el ventral es fuertemente cóncavo, lo que hace que la hoja escapular sea más angosta en su parte media. El borde distal esta dañado por la erosión. El extremo dorso-proximal forma un ángulo recto, por lo tanto el proceso supraglenoideo no es muy marcado. La escápula de Drusilasaura deseadensis gen. et $\mathrm{sp}$. nov. está muy expandida proximalmente. La hoja escapular es curva en vista medial con una marcada depresión elongada próximodistalmente y es plana hacia la parte proximal. Su borde posterior es ligeramente cóncavo y de mayor grosor que el anterior. La depresión o cavidad supraglenoidea está suavemente marcada. Hacia la porción distal de la hoja escapular se observan surcos o arrugas longitudinales y subparalelas, que podrían relacionarse con la inserción muscular, probablemente el músculo romboideo (Schwarz et al., 2007) o ligamentos.

Hemapófisis. Dos hemapófisis incompletas fueron rescatadas (MPM-PV 2097/12 y /13), una de ellas soldada a la cara ventral de la $6^{\circ}$ ? vértebra caudal y la otra aislada. Se observa claramente en ellas los extremos proximales separados como en otros taxa de Camarasauromorpha (Salgado et al., 1997). No es posible observar las facetas articulares por falta de conservación del material. 

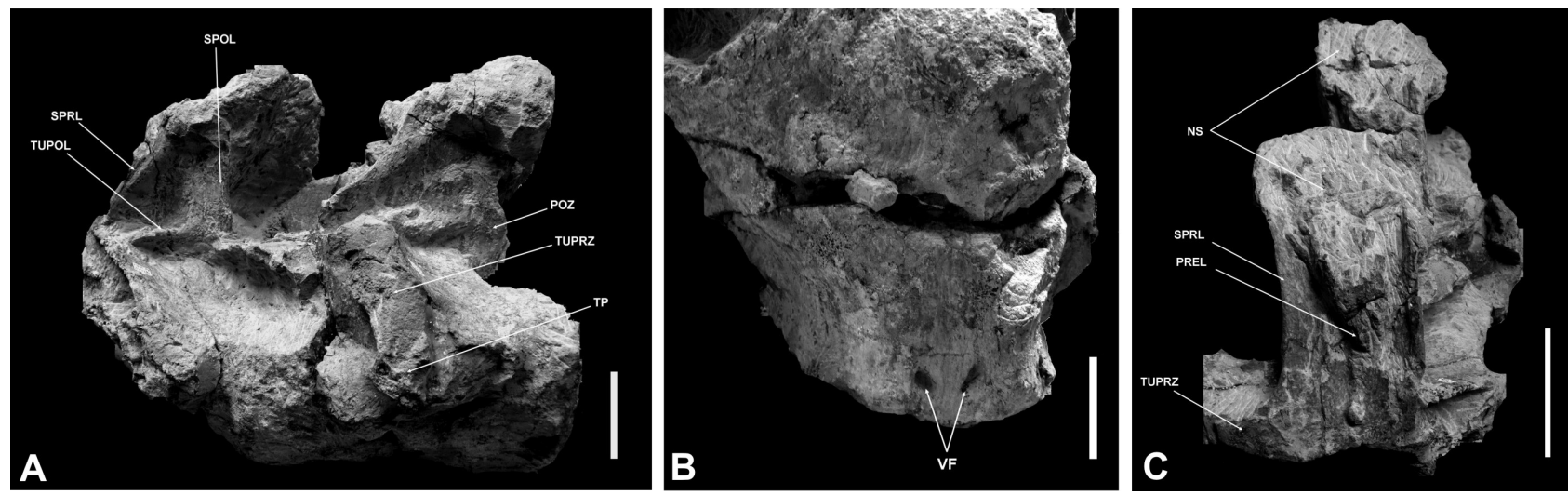

Figura 5. Drusilasaura deseadensis gen. et sp. nov., MPM-PV $2097 / 8$ y $/ 9$. A, $3^{\circ}$ ? y $4^{\circ}$ ? vértebras caudales en vista lateral; B, $3^{\circ}$ ? y $4^{\circ}$ ? vértebras caudales en vista ventral; C, $3^{\circ}$ ? y $4^{\circ}$ ? vértebras caudales en vista anterodorsal. Abreviaturas: NS, espina neural; POZ, postzigapófisis; PREL, lámina prespinal; SPOL, lámina espinopostzigapofisial; SPRL, lámina espinoprezigapofisial; TUPOL, lámina tuberopostzigapofisial; TUPRZ, tuberosidad prezigapofisial; TP, proceso transverso; VF, forámenes ventrales. Escalas = $10 \mathrm{~cm}$.

Figure 5. Drusilasaura deseadensis gen. et sp. nov., MPM-PV $2097 / 8$ y $/ 9,3^{\circ}$ ? and $4^{\circ}$ ? caudal vertebrae in lateral view. Abbreviations: NS, neural spine; POZ, postzygapophysis; PREL, prespinal lamina; SPOL, spinopostzygapophyseal lamina; SPRL, spinoprezygapophyseal lamina; TUPOL, tuberopostzygapophyseal lamina; TUPRZ, prezygapophyseal tuberosity; TP, transverse process; VF, ventral foramina Scale bars $=10 \mathrm{~cm}$.

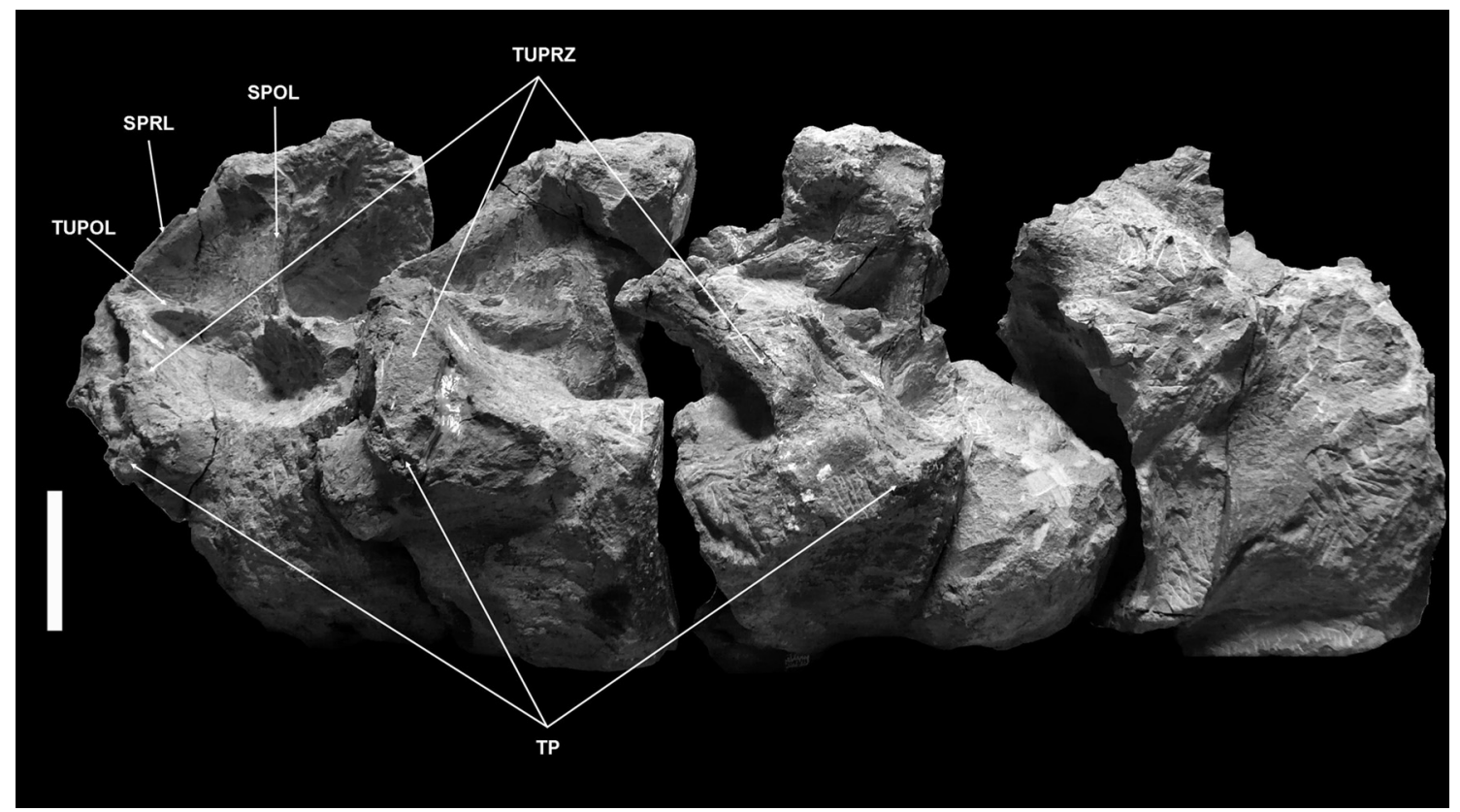

Figura 6. Drusilasaura deseadensis gen. et sp. nov.: MPM-PV 2097/8, $/ 9, / 10$ y $/ 11,3^{\circ}$ ?, $4^{\circ}$ ?, $5^{\circ}$ ? y $6^{\circ}$ ? vértebras caudales en vista lateral. Abreviaturas: SPRL, lámina espinoprezigapofisial; SPOL, lámina espinopostzigapofisial; TP, proceso transverso; TUPOL, lámina tuberopostzigapofisial; TUPRZ, tuberosidad prezigapofisial. Escala $=10 \mathrm{~cm}$.

Figure 6. Drusilasaura deseadensis gen. et sp. nov.: MPM-PV $2097 / 8, / 9, / 10$ y $/ 11,3^{\circ}$ ?, $4^{\circ}$ ?, $5^{\circ}$ ? y $6^{\circ}$ ? caudal vertebrae in lateral view. Abbreviations: SPRL, spinoprezygapophyseal lamina; SPOL, spinopostzygapophyseal lamina; TP, transverse process; TUPOL, tuberopostzygapophyseal lamina; TUPRZ, prezygapophyseal tuberosity. Scale bar $=10 \mathrm{~cm}$.

\section{COMPARACIONES}

\section{Comparación con otros titanosaurios}

Malawisaurus dixeyi (Haughton, 1928): esta especie del sureste de África muestra, a diferencia de Drusilasaura deseadensis gen. et sp. nov., una lámina prespinal solo presente en la porción terminal de las vértebras dorsales. En cuanto a las vértebras caudales, la más anterior de éstas muestra cierta similitud morfológica con Drusilasaura deseadensis gen. et sp. nov., la espina neural está expan- dida lateralmente, siendo más ancha que larga (Jacobs et al., 1993).

Baurutitan britoi: esta especie del Maastrichtiano del grupo Bauru, Brasil, hallada en la Formación Marília, miembro Serra da Galta (Kellner et al., 2005), presenta una similitud muy interesante con Drusilasaura deseadensis gen. et $\mathrm{sp}$. nov. que es la presencia de una tuberosidad prezigapofisial en las vértebras caudales. Esta estructura ubicada por detrás de la prezigapófisis, comienza por encima del proceso transverso y llega a interrumpir a la lámina espinoprezigapofisial 


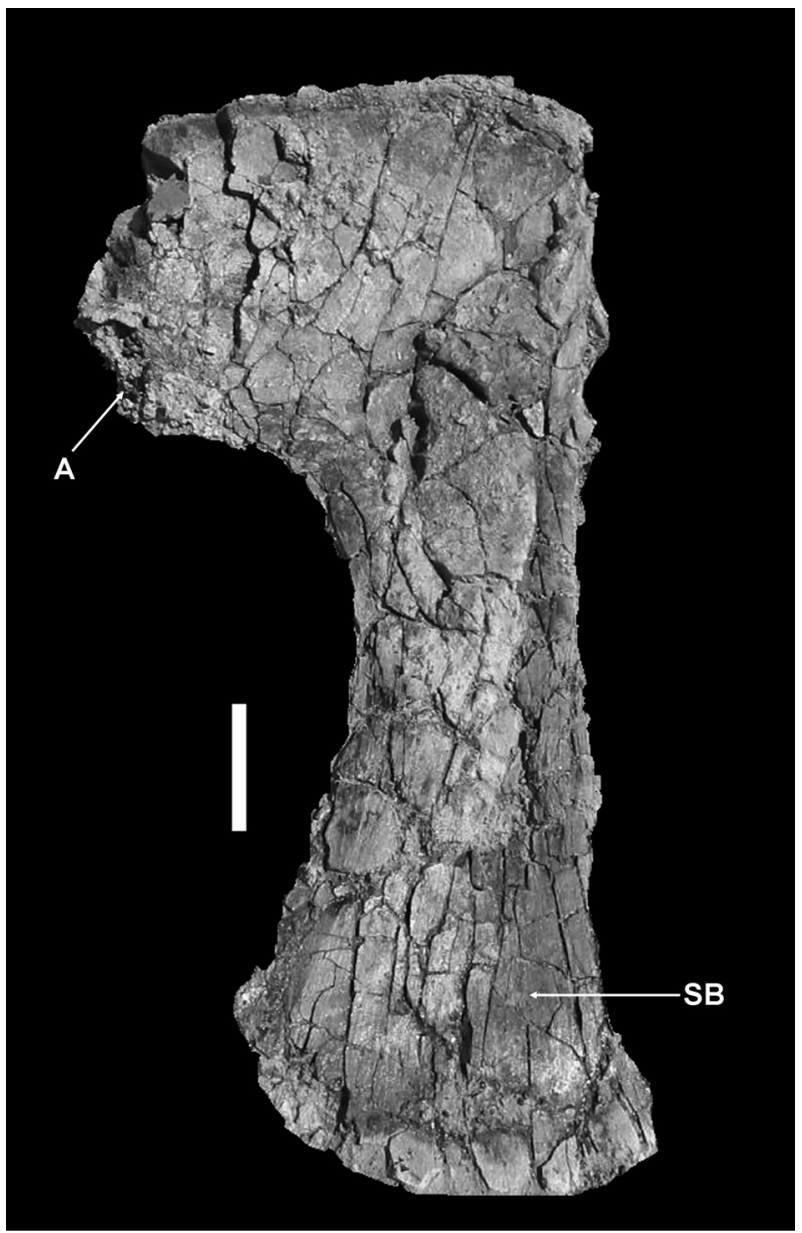

Figura 7. Drusilasaura deseadensis gen. et sp. nov., MPM-PV 2097/14, escápula izquierda en vista lateral. Abreviaturas: A, acromion; SB, hoja escapular. Escala $=30 \mathrm{~cm}$.

Figure 7. Drusilasaura deseadensis gen. et sp. nov., MPM-PV 2097/14, left scapula in lateral view. Abbreviations: A, acromion; SB, scapular blade. Scale bar $=30 \mathrm{~cm}$.

antes de que esta contacte a la prezigapófisis. Esta interrupción de la lámina se da en el Baurutitan britoi sólo hasta la segunda vértebra caudal, mientras que en Drusilasaura deseadensis gen. et $\mathrm{sp}$. nov. lo hace al menos hasta la 4²? (MPM-PV 2097/8) vértebra caudal. Una diferencia notoria entre estas dos especies es que la primera vértebra caudal de Baurutitan britoi es biconvexa, mientras que en Drusilasaura deseadensis gen. et sp. nov. sería procélica ya que la última sacra muestra un centro vertebral procélico al igual que la $2^{\circ}$ vértebra caudal. En Baurutitan britoi la lámina postespinal en la última vértebra sacra es levemente expandida hacia el ápice de la espina neural mientras que en Drusilasaura deseadensis gen. et sp. nov. es notable. También la lámina prespinal en las vértebras caudales muestra una importante expansión hacia el ápice de la espina neural la cual está ausente en Baurutitan britoi (Figura 8). En Baurutitan britoi la espina neural de las dos vértebras caudales más anteriores es lateralmente expandida siendo levemente más ancha que larga. En Drusilasaura deseadensis gen. et sp. nov. en cambio, esta expansión lateral es de mayor magnitud y se mantiene al menos hasta la $5^{\circ}$ ? vértebra cau- dal, como lo muestra la Figura 9. La orientación posterior de las espinas neurales de las vértebras caudales anteriores es compartida por ambas especies, no así en la vértebra sacra que en Drusilasaura deseadensis gen. et sp. nov. se presenta vertical y en Baurutitan britoi posteriormente orientada.

Epachthosaurus sciuttoi: este titanosaurio chubutense proveniente de la Formación Bajo Barreal, muestra las espinas neurales de las vértebras dorsales anteriores inclinadas posteriormente más de $20^{\circ}$ y la presencia de la articulación hipósfeno-hipantro (Powell, 1990; Martínez et al., 2004), ambos caracteres ausentes en Drusilasaura deseadensis gen. et sp. nov. Ambos taxa comparten sinapomorfías clásicas de Titanosauria como la presencia de pleurocelos acuminados posteriormente y la procelia de las vértebras caudales, así como también la presencia de la lámina prespinal que recorre toda la extensión de la espina neural en las vértebras dorsales, además de los arcos hemales con extremos proximales abiertos.

Argentinosaurus huinculensis Bonaparte \& Coria, 1993: éste gigantesco saurópodo proveniente de la Formación Río Limay de la provincia de Neuquén presenta en las vértebras dorsales, a diferencia de Drusilasaura deseadensis gen. et sp. nov., la articulación accesoria hipósfeno-hipantro, láminas accesorias a la lámina espinodiapofisial ubicadas anteriormente, una lámina postzigadiapofisial extensa que contacta la lámina espinodiapofisial en un sector próximo al extremo de la diapófisis, una única lámina espinodiapofisial, la espina neural sensiblemente inclinada posteriormente en la vértebra dorsal más anterior y mostrando una leve expansión lateral en la porción apical.

Opisthocoelicaudia skarzynskii Borsuk-Bialynicka, 1977: a diferencia de esta especie del Cretácico Superior de Mongolia, Drusilasaura deseadensis gen. et sp. nov. presenta una espina neural simple desarrollada verticalmente en las vértebras dorsales anteriores mientras que éste presenta una espina neural bífida inclinada posteriormente más de $20^{\circ}$. En ambos titanosaurios las vértebras dorsales carecen de la articulación hipósfeno-hipantro, la lámina prespinal está desarrollada a lo largo de toda la espina neural, los pleurocelos poseen forma de ojos acuminados posteriormente. En cuanto a las vértebras caudales, el espécimen asiático se diferencia de Drusilasaura deseadensis gen. et sp. nov. por presentar centros opistocélicos, espina neural expandida longitudinalmente y proyectada posteriormente, ausencia de tuberosidad prezigapofisial. La escápula de Opisthocoelicaudia skarzynskii muestra en vista lateral una convexidad de la hoja escapular notablemente desarrollada y el borde posterior de esta no recto (Borsuk-Bialynicka, 1977). En Drusilasaura deseadensis gen. et $\mathrm{sp}$. nov. la hoja escapular no muestra una convexidad de tal magnitud y el borde posterior es recto. La morfología del borde anterior de la hoja escapular, no recto en ningún tramo, es compartida por ambos.

Neuquensaurus australis (Lydekker, 1893), Saltasaurus loricatus Bonaparte \& Powell, 1980 y Rocasaurus muniozi Salgado \& Azpilicueta, 2000: con estas formas del clado Saltasaurinae, presentes tanto en el norte del país como en Patagonia, Drusilasaura deseadensis gen. et sp. nov. se di- 

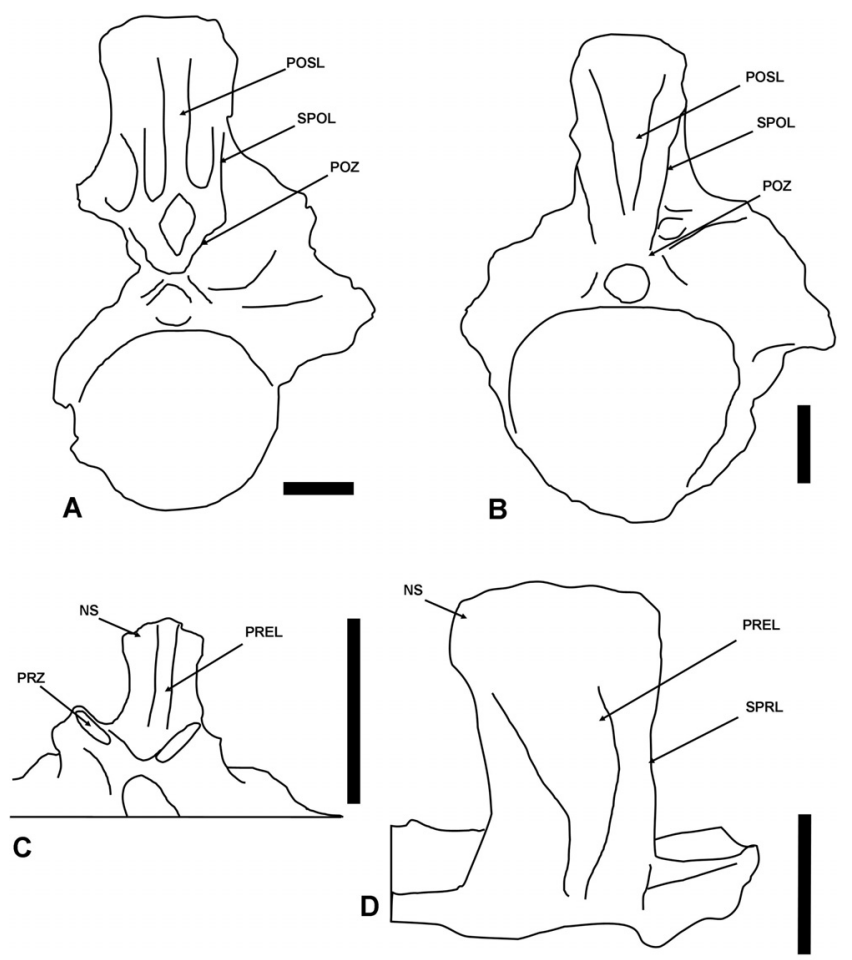

Figura 8. A, Baurutitan britoi, MCT 1490-R, última vértebra sacra en vista posterior; B, Drusilasaura deseadensis gen. et sp. nov., MPM-PV 2097/5, última vértebra sacra en vista posterior; C, Baurutitan britoi, MCT 1490-R, vértebra caudal $4^{\circ}$ en vista anterior; D, Drusilasaura deseadensis gen. et sp. nov., MPM-PV 2097/ $9,4^{\circ}$ ? vértebra caudal en vista anterior. Abreviaturas: NS, espina neural; POSL, lámina postespinal; POZ, postzigapófisis; PREL, lámina prespinal; PRZ, prezigapófisis; SPOL, lámina espinopostzigapofisial; SPRL, lámina espinoprezigapofisial. Escalas $=5 \mathrm{~cm}(A, B) ; 10 \mathrm{~cm}(C, D)$.

Figure 8. A, Baurutitan britoi, MCT 1490-R, last sacral vertebrae in posterior view; B, Drusilasaura deseadensis gen. et sp. nov.: MPM-PV 2097/5, last sacral vertebrae in posterior view; C, Baurutitan britoi, MCT 1490-R, $4^{\circ}$ caudal vertebra in anterior view; D, Drusilasaura deseadensis gen. et sp. nov.: MPM-PV 2097/9, $4^{\circ}$ ? Caudal vertebra in anterior view. Abbreviations: NS, neural espine; POSL, postspinal lamina; POZ, postzygapophysis; PREL, prespinal lamina; PRZ, prezygapophysis; SPOL, spinopostzygapophyseal lamina; SPRL, spinoprezygapophyseal lamina. Scale bars $=5 \mathrm{~cm}(A, B) ; 10 \mathrm{~cm}(C, D)$.

ferencia por carecer de los caracteres sinapomórficos del clado, que son, centros de las vértebras caudales bajos, más anchos que altos, y el borde anterior de la espina neural ubicada posteriormente con respecto al margen anterior de las postzigapófisis en las vértebras caudales medias (Salgado et al., 1997). También en estos tres taxa la espina neural en las vértebras dorsales anteriores se presenta inclinada posteriormente más de $20^{\circ}$, lo cual contrasta con la espina neural vertical de Drusilasaura deseadensis gen. et sp. nov. Con Neuquensaurus australis muestra diferencias en la primera vértebra caudal la cual en esta forma es biconvexa y en nuevo taxon es procélica (Powell, 1992). Con Saltasaurus loricatus difieren en que éste no presenta una cavidad interzigapofisial en la primera vértebra caudal (Bonaparte \& Powell, 1980) la que sí está presente en Drusilasaura deseadensis gen. et $\mathrm{sp}$. nov.; y en que en el titanosaurio norteño, al igual que en Rocasaurus muniozi, existe una cavidad ventral dividida por

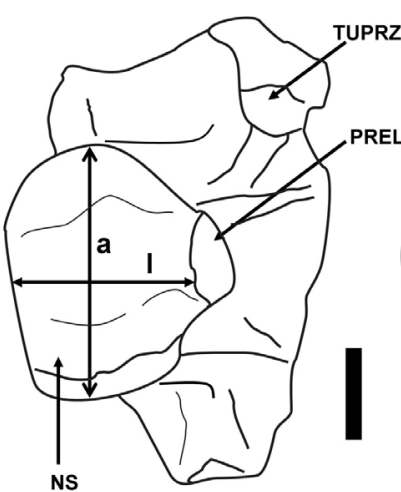

A

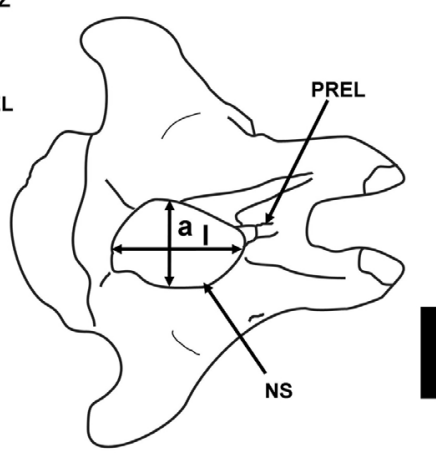

$\mathbf{B}$
Figura 9. A, Drusilasaura deseadensis gen. et sp. nov., MPM-PV 2097/10, $5^{\circ}$ ? vértebra caudal en vista dorsal; B, Baurutitan britoi, MCT 1490-R, $5^{\circ}$ vértebra caudal en vista dorsal. Abreviaturas: NS, espina neural; PREL, lámina prespinal; TUPRZ, tuberosidad prezigapofisial. Escalas $=5 \mathrm{~cm}$.

Figure 9. A, Drusilasaura deseadensis gen. et sp. nov., MPM-PV 2097/10, $5^{\circ}$ ? caudal vertebrae in dorsal view; B, Baurutitan britoi, MCT $1490-R, 5^{\circ}$ caudal vertebrae in dorsal view. Abbreviations: NS, neural espine; PREL, prespinal lamina; TUPRZ, prezygapophyseal tuberosity. Scale bars $=5 \mathrm{~cm}$.

un septo en las vértebras caudales, rasgo ausente en Drusilasaura deseadensis gen. et $\mathrm{sp}$. nov. Con respecto a la escápula, en Drusilasaura deseadensis gen. et sp. nov. como en Saltasaurus loricatus el borde anterior de la hoja escapular no es recto en ninguno de sus tramos, mientras que en Neuquensaurus australis el borde anterior es cóncavo en su porción proximal y recto en su sector distal.

Aeolosaurus rionegrinus Powell, 1987, Aeolosaurus colhuehuapensis y Gondwanatitan faustoi Kellner \& Azevedo, 1999: estas especies pertenecientes al clado Aeolosaurini, presentan sinapomorfías ausentes en el titanosaurio santacruceño Drusilasaura deseadensis gen. et $\mathrm{sp}$. nov. tales como: cuerpos caudales anteriores y medios con el margen anterior inclinado hacia adelante; arcos neurales dispuestos sobre el borde anterior del centro en las vértebras caudales medias; espina neural inclinada hacia adelante al menos en las caudales medias y las facetas articulares de las prezigapófisis y postzigapófisis alargadas anteroposteriormente en las vértebras caudales anteriores y medias (Franco-Rosas et al., 2004). En Drusilasaura deseadensis gen. et sp. nov. los arcos neurales de las vértebras caudales están posicionados anteriormente con respecto al centro vertebral, pero no alcanzan a ubicarse en el borde anterior del centro, las facetas articulares de las pre y postzigapófisis son de moderado alargamiento y los cuerpos vertebrales muestran los márgenes anteriores verticales. Con Gondwanatitan faustoi además se diferencia en que él se presentan las espinas neurales en las vértebras dorsales anteriores inclinadas posteriormente más de $20^{\circ}$ (Kellner \& Azevedo, 1999), siendo vertical en Drusilasaura deseadensis gen. et sp. nov.; con Aeolosaurus colhuehuapensis por presentar éste, la primera vértebra caudal biconvexa y carecer en ella de cavidad interzigapofisial.

Drusilasaura deseadensis gen. et sp. nov. presenta un carácter en las vértebras caudales que es considerado 
sinapomórfico para un grupo de titanosaurios denominado Lognkosauria. Este clado se acuñó basado en las siguientes sinapomorfías: presencia de expansiones laterales de la espina neural en las vértebras cervicales posteriores, que son más anchas que el centro vertebral; vértebras cervicales posteriores con una altura de 1,5 veces la longitud del centro vertebral; presencia de una profunda y extendida cavidad supradiapofisial en las vértebras cervicales posteriores; cara articular posterior del centro vertebral en las vértebras cervicales posteriores con una relación largo/alto menor a 1,5 ; vértebra caudal más anterior con espina neural transversalmente elongada (Calvo et al., 2007a). Este último es el carácter que está presente en Drusilasaura deseadensis gen. et $\mathrm{sp}$. nov., aunque ampliado ya que no está restringido a la vértebra más anterior sino que se extiende hasta la $4^{\circ}$ ? vértebra caudal. Se trata de la única sinapomorfía de las vértebras caudales del clado, por lo que su presencia en Drusilasaura deseadensis gen. et sp. nov. podría establecer un parentesco cercano entre esta especie y el clado Lognkosauria. Lamentablemente no existen materiales cervicales de Drusilasaura deseadensis gen. et sp. nov. que son precisamente los que mayor cantidad de caracteres lognkosaurianos han brindado en Mendozasaurus neguyelap Gonzalez Riga, 2003 y Futalognkosaurus dukei Calvo et al., 2007. Recientemente en Navarrete et al. (2009), se ha propuesto la inclusión de Puertasaurus reuili Novas et al., 2005 a este clado, aunque basándose en caracteres morfológicos cervicales. Si bien esta incorporación no ha sido testeada por un análisis filogenético, se lo incluye tentativamente al clado con fines comparativos.

Por la presencia en Drusilasaura deseadensis gen. et sp. nov. del único carácter caudal considerado sinapomórfico de Lognkosauria, se compara a continuación, por separado, con los taxa pertenecientes a dicho clado.

\section{Comparación con titanosaurios Lognkosauria}

En la vértebra dorsal anterior MPM-PV 2097/1, Drusilasaura deseadensis gen. et $\mathrm{sp}$. nov. comparte con las demás formas del clado la ausencia de una articulación accesoria hipósfeno-hipantro, las diapófisis proyectadas lateralmente y de manera horizontal, los pleurocelos acuminados posteriormente, la espina neural simple, la lámina prespinal que recorre la totalidad de la espina neural y la presencia de una lámina espinodiapofisial, aunque en el nuevo saurópodo santacruceño esta estructura es doble diferenciándose una lámina espinodiapofisial anterior y otra posterior. Al igual que en Mendozasaurus neguyelap y Puertasaurus reuili el arco neural es vertical, el centro vertebral relativamente corto y las pre y postzigapófisis están medialmente inclinadas, mientras que en Futalognkosaurus dukei el arco neural está levemente inclinado posteriormente, el centro es más bien elongado y las pre y postzigapófisis son horizontales. Mendozasaurus neguyelap presenta oquedades infrapostzigapofisiales que están ausentes en Drusilasaura deseadensis gen. et sp. nov. y un pilar medial que soporta la lámina intraprezigapofisial y que en la forma santacruceña es reemplazado por dos pequeñas láminas centrointraprezigapofisiales. Puertasaurus reuili presenta dos láminas prezigoparapofisiales y dos láminas que nacen de la diapófisis que en su recorrido hacia la parapófisis se unifican (César Navarrete, com. pers.) mientras que en Drusilasaura deseadensis gen. et $\mathrm{sp}$. nov. ambas estructuras están representadas por una única lámina. Como en Mendozasaurus neguyelap y Puertasaurus reuili no existen, en Drusilasaura deseadensis gen. et sp. nov., láminas centroprezigapofisiales. También es compartida por estos tres taxa la presencia de tres cavidades visibles en vista lateral: una cavidad infraprezigapofisial de contorno subtriangular limitada por las láminas prezigaparapofisial, paradiapofisial y prezigadiapofisial (en Puertasaurus reuili se observan dos cavidades al tener dos láminas paraprezigapofisiales), una cavidad supradiapofisial limitada por las láminas espinopostzigapofisial, espinodiapofisial posterior y la postzigadiapofisial, y por último una cavidad infrapostzigapofisial limitada por las láminas centropostzigapofisial, postzigadiapofisial y la centrodiapofisial posterior. En Drusilasaura deseadensis gen. et sp. nov., a diferencia de Mendozasaurus neguyelap, no existen láminas espinoprezigapofisiales.

En las vértebras caudales del Drusilasaura deseadensis gen. et sp. nov., a diferencia de Mendozasaurus neguyelap, la expansión lateral de la espina neural está presente hasta al menos la $4^{\circ}$ ? vértebra caudal (MPM-PV 2097/9), mientras que en el titanosaurio mendocino sólo se da en la primera. En Futalognkosaurus dukei no es posible comprobar esto ya que fue recuperada sólo la primera vértebra caudal, la que también comparte la expansión lateral de la espina neural. En Puertasaurus reuili solo se cuenta con dos centros vertebrales caudales procélicos, por lo que su comparación no se puede realizar.

En Drusilasaura deseadensis gen. et sp. nov. existe la estructura denominada tuberosidad prezigapofisial, mientras que en el resto de los taxa del clado ésta está ausente. Los forámenes ventrales también son un carácter único del ejemplar santacruceño. Futalognkosaurus dukei muestra a diferencia de Drusilasaura deseadensis gen. et sp. nov. la presencia de una lámina supraespinal que comunica las láminas pre y postespinales, dos cavidades supraespinales delimitadas por la lámina prespinal, las láminas laterales en vista anterior de la vértebra caudal más anterior y la presencia de dos pequeñas láminas infraprespinales producto de la bifurcación de la lámina prespinal (Calvo et al., 2007b). Se haya ausente en éste la expansión de la lámina prespinal presente en Drusilasaura deseadensis gen. et sp. nov.

La escápula preservada de Drusilasaura deseadensis gen. et sp. nov. puede ser comparada dentro de Lognkosauria únicamente con la de Mendozasaurus neguyelap. La escápula de Drusilasaura deseadensis gen. et sp. nov. es de mayor tamaño, aproximadamente un $30 \%$ más. El borde dorsal de la hoja escapular es levemente cóncavo en ambos taxa, el proceso supraglenoideo en Drusilasaura deseadensis gen. et sp. nov. se presenta menos marcado que en Mendozasaurus neguyelap. En este la hoja escapular posee un borde anterior cóncavo en su porción proximal y recto en su parte distal, mientras que en Drusilasaura deseadensis gen. et sp. nov. 
no hay rectificación en su recorrido. El borde posterior de la hoja escapular es esencialmente recto en Drusilasaura deseadensis gen. et sp. nov. mientras que en Mendozasaurus neguyelap es sensiblemente cóncavo.

\section{DISCUSIÓN Y CONSIDERACIONES FINALES}

El material MPM PV 2097 es considerado como perteneciente al nuevo género y especie de titanosáurido Drusilasaura deseadensis gen. et sp. nov. Su inclusión en el clado Titanosauria se basa en la presencia de pleurocelos acuminados en las vértebras dorsales y la procelia de las vértebras caudales anteriores (Salgado et al., 1997); asimismo se incluye dentro de Titanosauridae por la ausencia de la articulación accesoria hipósfeno-hipantro y excluido de formas más derivadas como los Saltasaurinae por no mostrar centros caudales anteriores comprimidos dorso-ventralmente, más anchos que altos.

Internamente el análisis del clado Titanosauria ha sufrido numerosos cambios y controversias en los últimos tiempos (Salgado, 2003; Wilson \& Upchurch, 2003), así como también la generación de nuevas e interesantes divisiones internas. De estos análisis surge la propuesta de Calvo et al. (2007a) formando un nuevo clado, Lognkosauria, para incluir a las especies Mendozasaurus neguyelap, Futalognkosaurus dukei y posiblemente Puertasaurus reuili. Si bien Drusilasaura deseadensis gen. et sp. nov. presenta sólo una de las sinapomorfías que definen a Lognkosauria, se considera de importancia ya que es el único carácter sinapomórfico de las vértebras caudales que definen al clado. Por lo tanto, es posible sugerir la inclusión de Drusilasaura deseadensis gen. et sp. nov. en el clado Lognkosauria, lo que podrá ser confirmado o no, con un futuro análisis filogenético.

Dentro de la asociación de caracteres que definen este novedoso tiranosaurio, deben distinguirse los interpretados como derivados, de los considerados como autapomórficos. Dentro del primer grupo se incluyen a: "expansión de la lámina postespinal hacia el ápice de la espina neural en la última vértebra sacra" y "tuberosidad prezigapofisial contactando la lámina prespinal hasta la $4^{\circ}$ ? vértebra caudal”. Estos rasgos se presentan en Drusilasaura deseadensis gen. et sp. nov. como acentuaciones o modificaciones de caracteres similares descriptos previamente en Baurutitan britoi por lo que son considerados como caracteres derivados.

Por su parte los caracteres: (i) "presencia en las vértebras dorsales anteriores, de dos robustas láminas espinodiapofisiales, una anterior y otra posterior que delimitan una elongada y profunda cavidad supradiapofisial"; (ii) "presencia de una pequeña lámina circumneural, que rodea el canal neural en vista posterior de la vértebra dorsal anterior"; (iii) "lámina prespinal expandidas hacia el ápice de la espina neural en al menos hasta la $5^{\circ}$ ? vértebra caudal"; (iv) "existencia de láminas tuberopostzigapofisiales en las vértebras caudales anteriores" y (v) "la presencia de forámenes ventrales en al menos la $4^{\circ}$ ? vértebra caudal", son todos considerados como autapomórficos de Drusilasaura deseadensis gen. et sp. nov. ya que no han sido descriptos previamente.
Como se esbozó previamente, Baurutitan britoi muestra numerosas similitudes con Drusilasaura deseadensis gen. et $\mathrm{sp}$. nov. como la expansión lateral de las espinas neurales en las vértebras caudales (aunque de menor magnitud y presente en menos elementos de la secuencia caudal) y la última sacra, la presencia de tuberosidad prezigapofisial y la orientación posterior de las espinas neurales de las vértebras caudales. Esto permite suponer un cercano parentezco entre estos taxa principalmente por la presencia de la tuberosidad prezigapofisial en ambos, siendo este un carácter sólo descripto en estos dos saurópodos. Asimismo la presencia del carácter sinapomórfico caudal de los longkosaurios (expansión lateral de la espina neural siendo más ancha que larga) también en Baurutitan britoi, reafirma la estrecha relación entre estos dos titanosaurios y plantea un probable vínculo entre los Lognkosauria y Baurutitan britoi, lo cual deberá ser ratificado con un análisis filogenético.

Las expansiones laterales tanto de las vértebras cervicales como de las caudales que caracterizan a los lognkosaurios podrían estar relacionadas de alguna manera con el notable gigantismo del clado, teniendo en cuenta que las formas descriptas superan ampliamente los $20 \mathrm{~m}$ de longitud. Quizá estas estructuras cumplieron una función biomecánica importante como refuerzo otorgando mayor robustez axial. Esta posibilidad deberá ser explorada mediante futuros estudios de biomecánica vertebral.

Un punto interesante en relación a la edad de los sedimentos portadores de Drusilasaura deseadensis gen. et $\mathrm{sp}$. nov. es que se trata de niveles más modernos que los que han brindado los principales hallazgos de la Formación Bajo Barreal. La edad asignada, Cenomaniano tardío-Turoniano temprano para estos últimos niveles (Lamanna et al., 2002), se corresponde con los registros faunísticos de la parte superior del Miembro Inferior de la Formación Bajo Barreal.

Drusilasaura deseadensis gen. et sp. nov., en cambio, fue hallado en niveles estratigráficamente altos del Miembro Superior de dicha formación, suprayacidos en forma concordante por la Formación Laguna Palacios asignada al Santoniano-Maastrichtiano (Sciutto, 1981; Fitzgerald et al., 1990; Bridge et al., 2000). De este modo el rango de edad de Drusilasaura deseadensis gen. et sp. nov. podría extenderse hasta el Turoniano Superior e incluso hasta el Coniaciano, estando en consonancia esto con la posible edad de otros dos miembros del clado Lognkosauria, Futalognkosaurus dukei asignado al Turoniano-Coniaciano (Calvo et al., 2007a) y Mendozasaurus neguyelap al Turoniano tardío-Coniaciano tardío (González Riga, 2005). Por su parte Puertasaurus reuili, de ser correcta su asignación temporal, sería el Lognkosauria más moderno (si bien aún su asignación al clado es tentativa), alcanzando el Maastrichtiano temprano (Novas et al., 2005) del sudoeste de Patagonia, en la Formación Pari Aike.

Así, este nuevo titanosaurio santacruceño, Drusilasaura deseadensis gen. et sp. nov., junto con el de Argyrosaurus superbus conforman los más grandes Sauropoda registrados hasta ahora en la Formación Bajo Barreal. 


\section{AGRADECIMIENTOS}

Agradecemos a la familia Ortiz de Zárate, propietaria de la estancia María Aike, por su generosa hospitalidad y colaboración. Personal de la estancia María Aike. Municipalidad de Perito Moreno (intendente Moro y equipo), G. Arrigoni y personal del Museo del Petróleo. A la Facultad de Ciencias Naturales de la Universidad Nacional de la Patagonia San Juan Bosco. A F. Acuña, M. Tejedor, F. Goin, F. Pinto, y la empresa Skanska. L. Ibiricu, E. Ivany, M. Luna, M.E. Palacios, S. Cardozo, alumnos pasantes de la Fundación Antorchas: E. Balverdi, V. Mansilla, A. Rasgido, F. Barrionuevo, K. Boskamp, L. Cárdenas, R. A. Molina por la colaboración en campo y en la preparación. A J. Calvo, L. Salgado, M. Lamanna y M. Márquez por su excelente predisposición como fuentes de consulta. A R. Candeiro por la traducción del resumen al portugués. A los revisores del trabajo por sus valiosos aportes.

\section{REFERENCIAS}

Apesteguía, S. 2004. Bonitasaura salgadoi gen.et sp. nov.: a beaked sauropod from the Late Cretaceous of Patagonia. Naturwissenschaften, 91:493-497. doi:10.1007/s00114-004-0560-6

Archangelsky, S.; Bellosi, E.S.; Jalfin, G.A. \& Perrot, C. 1994. Palynology and alluvial facies from the mid-Cretaceous of Patagonia, subsurface of San Jorge Basin, Argentina. Cretaceous Research, 15:127-142.

Behrensmeyer, A. 1990. Taphonomy. In: D. Briggs \& P. Crowther (eds.) Palaeobiology, a synthesis. Blackwell Scientific Publications, p. 232-235.

Bonaparte, J.F. 1986. History of the terrestrial Cretaceous vertebrates of Gondwana. In: CONGRESO ARGENTINO DE PALEONTOLOGÍA Y BIOESTRATIGRAFÍA, 4, 1986. Actas, Mendoza, 2:63-95.

Bonaparte, J.F. \& Coria, R. 1993. Un nuevo y gigantesco saurópodo titanosaurio de la Formación Río Limay (Albiano-Cenomaniano) de la provincia del Neuquén, Argentina. Ameghiniana, 30(3):271-282.

Bonaparte, J.F. \& Gasparini, Z.B. 1979. Los saurópodos de los Grupos Neuquén y Chubut, y sus relaciones cronológicas. In: CONGRESO GEOLÓGICO ARGENTINO DE PALEONTOLOGÍA Y BIOESTRATIGRAFÍA, 7, 1979. Actas, Neuquén, 2:393-406.

Bonaparte, J.F. \& Powell, J.E. 1980. A continental assemblage of tetrapods from the Upper Cretaceous beds of El Brete, Northwestern Argentina (Sauropoda-Coelurosauria Carnosauria-Aves). Mèmoires de la Sociète Gèologique de France, Nouvelle Sèrie 139:19-28.

Borsuk-Bialynicka, M. 1977. A new camarasaurid sauropod Opisthocoelicaudia gen. n. sp. n. from the Upper Cretaceous of Mongolia. Paleontologia Polonica, 37:5-64.

Bridge, J.; Jalfin, G. \& Georgieff, S. 2000. Geometry, lithofacies and spatial distribution of Cretaceous fluvial sandstones bodies, San Jorge basin, Argentina: outcrop analog for the hydrocarbon-bearing Chubut Group. Journal of Sedimentary Research, 70(2):341-359. doi:10.1306/2DC40915-0E47-11D7-8643000102C1865D

Calvo, J.O. \& Bonaparte, J.F. 1991. Andesaurus delgadoi gen. et sp. nov. (Saurischia, Sauropoda) dinosaurio Titanosauridae de la Formación Río Limay (Albiano-Cenomaniano), Neuquén, Argentina. Ameghiniana, 28:303-310.
Calvo, J.O. \& González Riga, B. 2003. Rinconsaurus caudamirus gen. et sp. nov., a new titanosaurid (Dinosauria, Sauropoda) from the late Cretaceous of Patagonia, Argentina. Revista Geológica de Chile, 30(2):333-353.

Calvo, J.O.; Porfiri, J.D.; González Riga, B.J. \& Kellner, A.W. 2007a. Anatomy of Futalognkosaurus dukei Calvo, Porfiri, González Riga \& Kellner, 2007 (Dinosauria, Titanosauridae) from the Neuquén Group (Late Cretaceous), Patagonia, Argentina. Arquivos do Museu Nacional, 65(4):511-526.

Calvo, J.O.; Porfiri, J.D.; González-Riga, B.J. \& Kellner, A.W. 2007b. A new Cretaceous terrestrial ecosystem from Gondwana with the description of a new sauropod dinosaur. Anais da Academia Brasileira de Ciências, 79(3):529-541. doi:10.1590/ 50001-37652007000300013

Casal, G. \& Ibiricu, L. 2010. Materiales asignables a Epachthosaurus Powell, 1990 (Sauropoda: Titanosauria), de la Formación Bajo Barreal, Cretácico Superior, Chubut, Argentina. Revista Brasileira de Paleontologia, 13(3):247-256. doi:10.4072/rbp.2010.3.08

Casal, G.; Martínez, R.; Luna, M.; Sciutto, J.C. \& Lamanna, M. 2007. Aeolosaurus colhuehuapensis sp. nov. (Sauropoda, Titanosauria) de la Formación Bajo Barreal, Cretácico Superior de Argentina. Revista Brasilera de Paleontologia, 10(1):53-62. doi:10.4072/rbp.2007.1.05

Filippi, S. \& Garrido, A.C. 2008. Pitekunsaurus macayai gen. et sp. nov., nuevo titanosaurio (Saurischia, Sauropoda) del Cretácico Superior de la Cuenca Neuquina, Argentina. Ameghiniana, 45(3):575-590.

Fitzgerald, M.G.; Mitchum, R.M., Jr.; Uliana, M.A. \& Biddle, K.T. 1990. Evolution of the San Jorge Basin, Argentina. American Association of Petroleum Geologist Bulletin, 74(6):879-920.

Franco-Rosas, A.C.; Salgado, L; Rosas, C. \& Souza Carvalho, I. 2004. Nuevos materiales (Sauropoda) en el Cretácico Superior de Mato Grosso, Brasil. Revista Brasileira de Paleontologia, 7(3):329-336.

González Riga, B.J. 2003. A new titanosaur (Dinosauria, Sauropoda) from the Upper Cretaceous of Mendoza Province, Argentina. Ameghiniana, 40(2):155-172.

González Riga, B.J. 2005. Nuevos restos fósiles de Mendozasaurus neguyelap (Sauropoda, Titanosauria) del Cretácico tardío de Mendoza, Argentina. Ameghiniana, 42(3):535-548.

González Riga, B.J. \& Astini, R.A. 2007. Preservation of large titanosaur sauropods in overbank fluvial facies: a case study in the Cretaceous of Argentina. Journal of South American Earth Sciences, 23:290-303. doi:10.1016/j.jsames.2007.02.005

Gradstein, F.M.; Agterberg, F.P.; Ogg, J.G.; Hardenbol, J.; van Veen, P.; Thierry, J. \& Huang, Z. 1995. A Triassic, Jurassic, and Cretaceous timescale. In: W.A. Berggren; D.V. Kent; M.P. Aubry \& J. Hardenbol (eds.) Geochronology Time Scales and Global Stratigraphic Correlation, Society of Sedimentary Geology Special Publication, p. 95-126.

Gradstein, F.M.; Ogg, J.; Agterberg, F.P.; Hardenbol, J. \& van Veen, P. 1997. Some constraints on the Phanerozoic timescale. In: INTERNATIONAL GEOLOGICAL CONGRESS, 30, 1997. Proceedings, Beijing, p. 11-19.

Jacobs, L.L; Winkler, D.A.; Downs W.R. \& Gomani, E.M. 1993. New material of an early Cretaceous titanosaurid sauropod dinosaur from Malawi. Palaeontology, 36:523-534.

Kellner, A.W.A. \& Azevedo, S.A.K. 1999. A new sauropod dinosaur (Titanosauria) from the Late Cretaceous of Brazil. In: GONDWANA DINOSAUR SIMPOSIUM, 2, 1999. Proceedings, Tokio, 15:111-142. 
Kellner, A.; Almeida Campos, D. de \& Trotta, M. 2005. Description of a titanosaurid caudal series from the Bauru Group, Late Cretaceous of Brazil. Arquivos do Museu Nacional, 63(3):529-564.

Lamanna, M.; Martínez, R. \& Smith, J. 2002. A definitive abelisaurid theropod dinosaur from the Early Late Cretaceous of Patagonia. Journal of Vertebrate Paleontology, 22(1):58-69.

Leanza, A.F. 1958. Geología Regional. In: La Argentina. Suma de Geografía, Tomo I, Capitulo III. Editorial Peuser, p. 217-349.

Lesta, P. \& Ferello, R. 1972. Región Extraandina de Chubut y Norte de Santa Cruz. In: A. Leanza (ed.), Geología Regional Argentina, Academia Nacional de Ciencias, p. 602-687.

Lydekker, R. 1893. Contributions to the study of the fossil vertebrates of Argentina. I. The Dinosaurs of Patagonia. Anales Museo de La Plata, Sección Paleontología, 2:1-14.

Martínez, R., 1998. An articulated skull and neck of Sauropoda (Dinosauria: Saurischia) from the Upper Cretaceous of central Pategonia, Argentina. Journal of Vertebrate Paleontology, 18(3):61A.

Martínez, R.D.; Giménez, O.; Rodríguez, J.; Luna, M. \& Lamanna, M. 2004. An articulated specimen of the basal titanosaurian (Dinosauria: Sauropoda) Epachthosaurus sciuttoi from the Early Late Cretaceous Bajo Barreal Formation of Chubut province, Argentina. Journal of Vertebrate Paleontology, 24(1):107-120. doi:10.1671/9.1

Martínez, R.; Vita, J.; Lamanna, M. \& Ibiricu, L. 2006. A CT scan of a titanosauriform skull (Dinosauria: Sauropoda) from Central Patagonia, Argentina. Journal of Vertebrate Paleontology, 26(3):96A.

Martínez, R.; Vita, J. Navarrete, C.; Casal, G. \& Lamanna, M. 2009. Tomografía helicoidal computada de vértebras cervicales de un Titanosauriforme (Dinosauria: Sauropoda) del sur del Chubut. Ameghiniana, 46(4): 39.

Navarrete, C.; Casal, G. \& Martínez, R. 2008. Nuevos materiales de Titanosauridae (Lognkosauria?) de la Formación Bajo Barreal, Cretácico Superior, Santa Cruz, Argentina. In: CONGRESO LATINOAMERICANO DE PALEONTOLOGÍA DE VERTEBRADOS, 3, 2008. Libro de Resúmenes, Neuquén, p. 176.

Navarrete, C.; Novas, F. \& Martínez, R. 2009. Puertasaurus reuili (Sauropoda, Titanosauria), un posible integrante del clado Lognkosauria. Ameghiniana, 46(4):36-37.

Novas, F.; Salgado, L.; Calvo, J. \& Agnolín, F. 2005. Giant titanosaur (Dinosauria: Sauropoda) from the Late Cretaceous of Patagonia. Revista del Museo Argentino de Ciencias Naturales, 7(1):37-41.

Powell, J. E. 1987. The Late Cretaceous Fauna from Los Alamitos, Patagonia, Argentina. Part. VI. The titanosaurids. Revista del Museo Argentino Ciencias Naturales, 3(3):147-153.

Powell, J.E. 1990. Epacthosaurus sciuttoi gen. et sp. nov. Un nuevo dinosaurio saurópodo del Cretácico de Patagonia (Provincia del Chubut, Argentina). In: CONGRESO ARGENTINO DE
PALEONTOLOGÍA Y BIOESTRATIGRAFÍA, 5, 1990. Actas, Tucumán, 1:123-128.

Powell, J.E. 1992. Osteología de Saltasaurus loricatus (Sauropoda: Titanosauridae) del Cretácico Superior del noroeste Argentino. In: J.L. Sanz \& A.D. Buscalioni (eds.) Los dinosaurios y su entorno biótico, Instituto Juan de Valdes, p. 166-230.

Powell, J.E. 2003. Revision of South American Titanosaurid dinosaurs: palaeobiological, palaeobiogeographical and phylogenetic aspects. Records of the Queen Victoria Museum, 111:1-173.

Salgado, L. 2003. Should we abandon the name titanosauridae? Some comments on the taxonomy of titanosaurian sauropods (Dinosauria). Revista Española de Paleontología, 18(1):15-21.

Salgado, L. \& Azpilicueta, C. 2000. Un nuevo saltasaurino (Sauropoda, Titanosauridae) de la provincia de Río Negro (Formación Allen, Cretácico Superior), Patagonia, Argentina. Ameghiniana, 37:259-264.

Salgado, L. \& Coria, R.A. 1993. El género Aeolosaurus (Sauropoda. Titanosauridae) en la Formación Allen (CampanianoMaastrichtiano) de la Provincia de Río Negro, Argentina. Ameghiniana, 30(2):119-128.

Salgado, L. \& Coria, R.A. 1996. First evidence of an ankylosaur (Dinosauria, Ornithischia) in South America. Ameghiniana, 33(4):367-371.

Salgado, L.; Coria, R.A. \& Calvo, J.O. 1997. Evolution of titanosaurid sauropods I: phylogenetic analysis base on the postcranial evidence. Ameghiniana, 34(1):3-32.

Salgado, L.; García, R. \& Daza, J. 2006. Consideraciones sobre las láminas neurales de los dinosaurios saurópodos y su significado morfofuncional. Revista del Museo Argentino de Ciencias Naturales, 8(1):69-79.

Schwartz, D.; Frey, E. \& Meyer, E. A. 2007. Novel reconstruction of the orientation of the pectoral girdle in sauropods. The Anatomical Record 290:32-47. doi:10.1002/ar.20405

Sciutto, J.C. 1981. Geología del Codo del Río Senguerr, Chubut, Argentina. In: CONGRESO GEOLÓGICO ARGENTINO, 8, 1981. Actas, San Luis, 3:203-219.

Uliana, M.A. \& Legarreta, L. 1999. Jurásico y Cretácico de la Cuenca del Golfo San Jorge. In: R. Caminos (ed.) Geología Argentina, Servicio Geológico Minero Argentino/Instituto de Geología y Recursos Minerales, p. 496-510.

Umazano, A.M.; Bellosi, E.S.; Visconti, G. \& Melchor, R.N. 2007. Mechanisms of aggradation in fluvial systems influenced by explosive volcanism: an example from the Upper Cretaceous Bajo Barreal Formation, San Jorge Basin, Argentina. Sedimentary Geology, 203: 213-228. doi:10.1016/j.sedgeo.2007.12.001

Wilson, J.A. \& P. Upchurch. 2003. A revision of Titanosaurus Lydekker (Dinosauria, Sauropoda), the first dinosaur genus with a 'Gondwanan' distribution. Journal of Systematic Palaeontology, 1:125-160. doi:10.1017/s1477201903001044

Received in April, 2010; accepted in January, 2011. 